Check for updates

Cite this: Phys. Chem. Chem. Phys., 2021, 23, 19329

Received 30th June 2021,

Accepted 22nd August 2021

DOI: $10.1039 / \mathrm{d} 1 \mathrm{cp} 02973 \mathrm{~h}$

rsc.li/pccp

\title{
A computational investigation of the adsorption of small copper clusters on the $\mathrm{CeO}_{2}(110)$ surface $\dagger$
}

\author{
Rui Zhang, (D)*a Arunabhiram Chutia, (D)*b Alexey A. Sokol, (D) ${ }^{c}$ David Chadwick (D) ${ }^{a}$ \\ and C. Richard A. Catlow iD cd
}

\begin{abstract}
We report a detailed density functional theory (DFT) study of the geometrical and electronic properties, and the growth mechanism of a $\mathrm{Cu}_{n}(n=1-4)$ cluster on a stoichiometric, and especially on a defective $\mathrm{CeO}_{2}(110)$ surface with one surface oxygen vacancy, without using pre-assumed gas-phase $\mathrm{Cu}_{n}$ cluster shapes. This gives new and valuable theoretical insight into experimental work regarding debatable active sites of promising $\mathrm{CuO}_{x} / \mathrm{CeO}_{2}$-nanorod catalysts in many reactions. We demonstrate that $\mathrm{CeO}_{2}(110)$ is highly reducible upon $\mathrm{Cu}_{n}$ adsorption, with electron transfer from $\mathrm{Cu}_{n}$ clusters, and that a $\mathrm{Cu}_{n}$ cluster grows along the long bridge sites until $\mathrm{Cu}_{3}$, so that each $\mathrm{Cu}$ atom can interact strongly with surface oxygen ions at these sites, forming stable structures on both stoichiometric and defective $\mathrm{CeO}_{2}(110)$ surface. $\mathrm{Cu}-\mathrm{Cu}$ interactions are, however, limited, since $\mathrm{Cu}$ atoms are distant from each other, inhibiting the formation of $\mathrm{Cu}-\mathrm{Cu}$ bonds. This monolayer then begins to grow into a bilayer as seen in the $\mathrm{Cu}_{3}$ to $\mathrm{Cu}_{4}$ transition, with long-bridge site $\mathrm{Cu}$ as anchoring sites. Our calculations on $\mathrm{Cu}_{4}$ adsorption reveal a $\mathrm{Cu}$ bilayer rich in $\mathrm{Cu}^{+}$species at the $\mathrm{Cu}-\mathrm{O}$ interface.
\end{abstract}

\section{Introduction}

Ceria-based catalysts have been widely studied in the past thirty years, ${ }^{1,2}$ stimulated by their successful applications, for example as a promoter in the automotive three-way catalysts (TWCs). ${ }^{3}$ Ceria $\left(\mathrm{CeO}_{2}\right)$ crystals have a face-centred cubic fluorite structure, characterised by three low-index facets (100), (110), and (111). The material has a high oxygen storage capacity (OSC) as it can easily shift between $\mathrm{Ce}^{4+}$ and $\mathrm{Ce}^{3+}$, forming bulk and surface oxygen vacancies with consequent high reducibility, ${ }^{4}$ which is further enhanced in well-defined ceria nanostructures, such as nanoparticles, nanorods, and nanocubes which expose (111), (110)/(100), and (100) surfaces, respectively. ${ }^{5-7}$ Consequently, nanostructured ceria-based catalysts, such as $\mathrm{CuO}_{x} / \mathrm{CeO}_{2}$

\footnotetext{
${ }^{a}$ Dept of Chemical Engineering, Imperial College London, South Kensington Campus, London SW7 2AZ, UK. E-mail: rui.zhang13@imperial.ac.uk

${ }^{b}$ School of Chemistry, University of Lincoln, Lincoln LN6 7TS, UK.

E-mail: achutia@lincoln.ac.uk

${ }^{c}$ Dept of Chemistry, University College London, 20 Gordon St., London WC1H OAJ, UK

${ }^{d}$ School of Chemistry, Cardiff University, Park Place, Cardiff CF10 1AT, UK $\dagger$ Electronic supplementary information (ESI) available: Results and further discussion of some $\mathrm{Cu}_{n} / \mathrm{CeO}_{2}(110)$ structures with/out one surface oxygen vacancy. In addition, Cartesian coordinates of all the optimised structures of $\mathrm{Cu}_{n}(n=1-4) / \mathrm{CeO}_{2}(110)$ and $\mathrm{Cu}_{n}(n=1-4) / \mathrm{CeO}_{2}(110)-\mathrm{Ov}$ from both $\mathrm{DFT}+U$ and DFT+U+D3 calculations can be found here (ZIP). See DOI: 10.1039/d1cp02973h
}

catalysts, are active in many reactions, for example, the water gas shift (WGS) reaction ${ }^{8,9}$ and CO oxidation. ${ }^{10,11}$

The structure and properties of $\mathrm{CuO}_{x} / \mathrm{CeO}_{2}$ catalysts have been widely studied. Chen et al. used high angle annular dark field scanning transmission electron microscope (HAADF-STEM) and in situ infra-red spectroscopy, as well as density functional theory (DFT) calculations to provide experimental and theoretical evidence of a $\mathrm{Cu}$ bilayer on a $\mathrm{CeO}_{2}(111)$ surface. ${ }^{8} \mathrm{~A}$ top layer of $\mathrm{Cu}^{0}$ atoms were bonded with a bottom layer of mainly $\mathrm{Cu}^{+}$ions, which in turn were bonded with surface oxygen vacancies (in $\mathrm{a} \mathrm{Cu}^{+}-\mathrm{Ov}-$ $\mathrm{Ce}^{3+}$ form). This copper-ceria interfacial perimeter was identified as the active site for WGS. Kang et al. recently reported experimental and theoretical evidence of an active atomic $\left[\mathrm{Cu}(\mathrm{I}) \mathrm{O}_{2}\right]^{3-}$ site for $\mathrm{CO}$ oxidation which dynamically changed to/ from $\left[\mathrm{Cu}(\mathrm{II}) \mathrm{O}_{4}\right]^{6-}$ via an electrophilic $\left[\mathrm{Cu}(\mathrm{II}) \mathrm{O}_{2}\left(\eta^{2}-\mathrm{O}_{2}\right)\right]^{4-}$ intermediate on the $\mathrm{CeO}_{2}(111)$ surface, both of which had a lower HOMO energy compared to Cu clusters on the surface. ${ }^{10}$

Besides these combined experimental and theoretical studies, there are several computational studies focusing mainly on the atomic and electronic structures of $\mathrm{Cu} / \mathrm{CeO}_{2}(111)$ (since $\mathrm{CeO}_{2}(111)$ is the most stable surface ${ }^{12}$ ), employing density functional theory (DFT), commonly the DFT $+U$ approach, in which an effective Hubbard $U_{\text {eff }}$ parameter is used to consider on-site Coulomb repulsions. For example, Szabová et al. reported their most stable $\mathrm{Cu} / \mathrm{CeO}_{2}$ structure with one oxidised $\mathrm{Cu}^{+}$and one reduced surface $\mathrm{Ce}^{3+}$ furthest away from the $\mathrm{Cu}^{+}$, with the 
nearest neighbour surface oxygen ions bonding closely with the $\mathrm{Cu}^{+}{ }^{13}$ For a $\mathrm{Cu} / \mathrm{CeO}_{2-x}$ system, the $\mathrm{Cu}$ atom sited above an oxygen vacancy was reduced to $\mathrm{Cu}^{\delta-} \cdot \mathrm{Cu}$ adsorption on surface oxygen vacancies was reported less stable than on a stoichiometric surface, suggesting that $\mathrm{Cu}$ nucleation was unlikely on the reduced $\mathrm{CeO}_{2}$ (111) surface. Yang et al. calculated that small $\mathrm{Cu}_{n}(n=1-4)$ clusters bonding with surface oxygen ions on a stoichiometric $\mathrm{CeO}_{2}(111)$ surface, are positively charged and slightly polarised, showing shortened $\mathrm{Cu}-\mathrm{O}$ distances. ${ }^{14} \mathrm{Cu}_{2}$ and $\mathrm{Cu}_{3}$ adopted a planar shape, while the two-dimensional (2D) to $3 \mathrm{D}$ structural transition was predicted in $\mathrm{a} \mathrm{Cu}_{4}$ cluster, because of the comparable strengths of $\mathrm{Cu}-\mathrm{Cu}$ and $\mathrm{Cu}-\mathrm{O}$ interactions. Paz-Borbon et al. calculated planar geometries of all $\mathrm{Cu}_{n}$ $(n=1-5)$ clusters on a stoichiometric $\mathrm{CeO}_{2}(111)$ surface, due to strong $\mathrm{Cu}-\mathrm{O}$ interactions and charge transfer effects. $^{15}$ The number of surface $\mathrm{Ce}^{3+}$ ions increased with the $\mathrm{Cu}$ cluster size, with a maximum of three electrons transferred from a $\mathrm{Cu}_{5}$ cluster. Regarding ceria surface oxygen vacancies, Jerratsch et al. investigated $\mathrm{Ce}^{3+}$ localisation on a defective $\mathrm{CeO}_{2}(111)$ surface with a single oxygen vacancy. ${ }^{16}$ They found at least one $\mathrm{Ce}^{3+}$ ion was not the nearest neighbour (NN) to the vacancy from both DFT calculations and scanning-tunnelling microscopy (STM).

Recently, Ning et al., based on a detailed $\mathrm{H}_{2}$-temperature programmed reduction $\left(\mathrm{H}_{2}\right.$-TPR) and X-ray photoelectron spectra (XPS) study, reported that different ceria shapes (particles, rods, and cubes) significantly affected the dispersion and chemical properties of copper species of a $\mathrm{CuO} / \mathrm{CeO}_{2}$ catalyst. $^{11}$ They observed $\mathrm{CuO}_{x}$ mono- and bilayer (using HAADF-STEM) as the dominant species, particularly on ceria nanorods, which were rich in $\mathrm{Cu}^{+}$at the copper-ceria interface $\left(\mathrm{Cu}-\left[\mathrm{O}_{x}\right]-\mathrm{Ce}\right)$. The $\mathrm{CuO} /$ $\mathrm{CeO}_{2}$-nanorod catalyst had the highest concentration of surface $\mathrm{Cu}^{+}$and oxygen vacancies, and thus showed a higher activity in CO oxidation, compared to catalysts with other shapes. Their experimental results strongly suggest that $\mathrm{CuO}_{x}$ mono- and bilayer are likely to form on $\mathrm{CeO}_{2}(110)$ and the copper-ceria interface may be rich in $\mathrm{Cu}^{+}$and oxygen vacancies. These atomic and electronic features are important for CO oxidation, ${ }^{17}$ as well as many more reactions such as $\mathrm{CO}_{2}$ hydrogenation to methanol, ${ }^{18} \mathrm{~N}_{2} \mathrm{O}$ decomposition, ${ }^{6}$ WGS, ${ }^{9}$ and NO reduction. ${ }^{19}$

As $\mathrm{CeO}_{2}(110)$ is less stable than $\mathrm{CeO}_{2}(111), \mathrm{Cu} / \mathrm{CeO}_{2}(110)$ is less studied. A number of computational studies are, however, reported. As with $\mathrm{Cu}$ adatom adsorption on $\mathrm{CeO}_{2}(111)$, a DFT study of Nolan suggested a $\mathrm{Cu}^{+}$ion and $\mathrm{a} \mathrm{Ce}^{3+}$ ion on a $\mathrm{CeO}_{2}(110)$ surface with significant local distortion. ${ }^{20}$ Cui et al. found $\mathrm{a} \mathrm{Cu}^{+}$or a $\mathrm{Cu}^{2+}$ ion on $\mathrm{CeO}_{2}(110)$ when locating the $\mathrm{Cu}$ adatom at different adsorption sites. ${ }^{21}$ Recently, Chutia et al. studied in detail the geometric and electronic properties of a $\mathrm{Cu}$ adatom adsorbed at different sites on $\mathrm{CeO}_{2}(110){ }^{22}$ They found the $\mathrm{O}_{\text {top }}$ initial structure ( $\mathrm{Cu}$ on top of a surface $\mathrm{O}$ ion) led to the most stable optimised structure, where the $\mathrm{Cu}$ was at an $\mathrm{O}-\mathrm{Ce}-\mathrm{O}$ long bridge site, showing one electron transfer and strong $\mathrm{Cu}-\mathrm{O}$ interactions. Ren et al. later studied the growth mechanism of a $\mathrm{Cu}_{n}(n=1-5)$ cluster on $\mathrm{CeO}_{2}(110) .{ }^{23}$ They observed a planar rhombus $\mathrm{Cu}_{4-\mathrm{p}}$ cluster transforming to a $3 \mathrm{D}$ tetrahedral $\mathrm{Cu}_{4-\mathrm{t}}$ cluster on the surface, and thus identified $\mathrm{Cu}_{3}$ as a critical size in $\mathrm{Cu}$ nucleation, which however was not favourable on $\mathrm{CeO}_{2}(110)$.
For a defective $\mathrm{CeO}_{2}(110)$ surface, the modelling study of Kullgren et al. reported that the most stable structure had an asymmetrical bridge site, in which one nearest surface oxygen moved towards the vacancy, bridging two nearby surface Ce species, and the $\mathrm{Ce}^{3+}$ ions were localised at an $\mathrm{NN}$ and $\mathrm{NNN}$ (next-nearest neighbour) position, respectively. ${ }^{24}$

Considering debatable active sites of promising $\mathrm{CuO}_{x} / \mathrm{CeO}_{2}-$ nanorod catalysts in many reactions, ${ }^{8,10,11,17,18}$ being it $\mathrm{Cu}$ species with different oxidation states, or the $\mathrm{Cu}$-ceria interface, the understanding of atomic and electronic properties of small $\mathrm{Cu}$ clusters, $\mathrm{a} \mathrm{CuO}_{x}$ mono- and bilayer on $\mathrm{CeO}_{2}(110)$, especially on a defective surface and at the copper-ceria interface, is thus of great interest and importance. However, there is a lack of comprehensive study of small $\mathrm{Cu}$ cluster morphologies and electronic interactions with $\mathrm{CeO}_{2}(110)$ surface. Therefore, in this study, we have conducted systematic DFT calculations to investigate the atomic and electronic properties, and the growth mechanism of a $\mathrm{Cu}_{n}(n=2-4)$ cluster on a stoichiometric, and especially on a defective $\mathrm{CeO}_{2}$ (110) surface with one surface oxygen vacancy, growing from a $\mathrm{Cu}_{n-1}$ cluster with an additional $\mathrm{Cu}$ atom placed at different adsorption sites. Our detailed investigation of small $\mathrm{Cu}_{n}(n=1-4)$ cluster adsorption on $\mathrm{CeO}_{2}(110)$, without using pre-assumed gas-phase $\mathrm{Cu}_{n}$ cluster shapes, provides fundamental understanding of highly reducible $\mathrm{CeO}_{2}(110)$ surface upon $\mathrm{Cu}_{n}$ adsorption, and strong $\mathrm{Cu}$-surface oxygen interactions with/out a surface oxygen vacancy, being the predominating factor in $\mathrm{Cu}_{n}(n=1-4)$ cluster growth on $\mathrm{CeO}_{2}(110)$, with relevance to experimental studies of $\mathrm{CuO}_{x} / \mathrm{CeO}_{2}$-nanorod catalysts. In the next section we present the theoretical methods employed, which we follow by the results and discussion first of $\mathrm{Cu}_{n}$ adsorption on a stoichiometric surface, and then on a defective surface. Our study leads to detailed and valuable understanding of structural and electronic properties of a $\mathrm{Cu}_{n}$ ( $n=1-4)$ cluster adsorbed on stoichiometric and defective $\mathrm{CeO}_{2}(110)$ surface, giving theoretical insights into the development of atomistic and electronic properties of a $\mathrm{CuO}_{x}$ mono/ bilayer at the $\mathrm{Cu}-\mathrm{O}$ interface on $\mathrm{CeO}_{2}(110)$.

\section{Computational details}

The Vienna Ab initio Simulation Package (VASP) was used to perform all the periodic spin-polarised DFT $+U$ calculations. $^{25-27}$ Blöchl's projector augmented wave (PAW) method was used to describe the core electrons of all atoms. ${ }^{28}$ The cut-off energy for the expansion of the plane-wave basis sets was set to $550 \mathrm{eV}$, with bulk energies converged to within $10^{-5} \mathrm{eV}$. A convergence criterion of $0.01 \mathrm{eV} \AA^{-1}$ was chosen for structural optimisation. The Perdew-Burke-Ernzerhof (PBE) version of the generalised gradient approximation (GGA) was used to carry out geometry optimisation and total energy calculations. ${ }^{29}$ The pristine $\mathrm{CeO}_{2}$ (110) surface was modelled by a $3 \times 3$ supercell with 7 atomic layers in which the bottom four layers were fixed to mimic the bulk of the system. The slab was cut from the bulk $\mathrm{CeO}_{2}$ with a theoretical lattice constant of $5.492 \AA$, which is close to the experimental value of $5.411 \AA$. In the direction 
perpendicular to the surface, a vacuum gap of $\sim 18 \AA$ was used. In all the calculations, $\mathrm{Cu}$ adsorption was only allowed on one of the two surfaces. Therefore, the dipole moment, due to $\mathrm{Cu}_{n}$ cluster adsorption, was corrected by using the methods proposed by Makov et al. and Neugebauer et al. as implemented in VASP. ${ }^{30,31} \mathrm{~A} 2 \times 2 \times 1 k$-point sampling grid was employed in all slab calculations, using the Monkhorst-Pack scheme. ${ }^{32}$ A Hubbard parameter $U^{33-35}$ in the Dudarev correction form ${ }^{35,36}$ was added to the energy functional, to correct the self-interaction error due to Ce localised 4 f-orbital electrons. In this study, a $U_{\text {eff }}$ value of $5.0 \mathrm{eV}$ was employed for both Ce 4 f-orbitals ${ }^{14,20,22,23}$ and $\mathrm{Cu} 3 \mathrm{~d}$-orbitals, ${ }^{22,37}$ which could correctly represent electron localisation in $\mathrm{Ce} 4 \mathrm{f}$ and $\mathrm{Cu} 3 \mathrm{~d}$ orbitals, respectively. A single $\mathrm{Cu}$ atom and $\mathrm{a} \mathrm{Cu}_{2}$ cluster in the gas phase were simulated using a $20 \times 20 \times 20 \AA^{3}$ cubic cell.

A two-stage optimisation procedure, originally proposed by Grau-Crespo ${ }^{38-40}$ was used to localise electrons in Ce 4 f orbitals during $\mathrm{CeO}_{2}(110)$ surface reduction, as the localisation is effected by lattice relaxation around the $\mathrm{Ce}^{3+}$ which is the response to the lower charge and larger radius of the $\mathrm{Ce}^{3+}$ compared with $\mathrm{Ce}^{4+}$. To generate this relaxation field Ce ions were replaced with larger La atoms. After geometry optimisation, the La atoms were then replaced by Ce atoms, which now have the appropriate surrounding relaxed configuration needed to localise an electron at the Ce site; the system is then fully geometry optimised.

Bader charges of different atoms were obtained by using the modified Bader charge analysis implemented by Tang et al. ${ }^{41}$ The Visualisation for Electronic and STructural Analysis (VESTA) package ${ }^{42}$ was employed to visualise different structures and spin densities.

The adsorption energy per $\mathrm{Cu}$ atom, $E_{\mathrm{ad}}$ of any given $\mathrm{Cu}_{n} /$ $\mathrm{CeO}_{2}(110)$ structure was calculated as follows,

$$
E_{\mathrm{ad}}=\frac{E\left(\mathrm{Cu}_{n} / \mathrm{CeO}_{2}\right)-n E\left(\mathrm{Cu}_{1}\right)-E\left(\mathrm{CeO}_{2}\right)}{n}
$$

where $E\left(\mathrm{Cu}_{n} / \mathrm{CeO}_{2}\right)$ is the energy of an optimised $\mathrm{Cu}_{n} / \mathrm{CeO}_{2}(110)$ structure, $E\left(\mathrm{Cu}_{1}\right)$ is the energy of a single $\mathrm{Cu}$ atom in the gas phase, $E\left(\mathrm{CeO}_{2}\right)$ is the energy of a relaxed/optimised stoichiometric $\mathrm{CeO}_{2}(110)$ surface, and $n$ is the number of $\mathrm{Cu}$ atoms. In this definition, more negative adsorption energies imply stronger, more favourable adsorption.

For the calculations involving reduced surfaces, the oxygen vacancy formation energy $E_{\mathrm{v}}$ was calculated as follows,

$$
E_{\mathrm{v}}=E\left(\mathrm{CeO}_{2 \mathrm{v}}\right)+\frac{1}{2} E\left(\mathrm{O}_{2}\right)-E\left(\mathrm{CeO}_{2}\right)
$$

where $E\left(\mathrm{CeO}_{2 \mathrm{v}}\right)$ is the energy of a relaxed/optimised defective $\mathrm{CeO}_{2}(110)-\mathrm{Ov}$ surface with one oxygen vacancy, and $E\left(\mathrm{O}_{2}\right)$ is the energy of a ground-state oxygen molecule in the gas phase.

Eqn (1) was also applied for the adsorption energy calculation of the $\mathrm{Cu}_{n} / \mathrm{CeO}_{2}(110)-\mathrm{Ov}$ systems, where the energy of an optimised $\mathrm{Cu}_{n} / \mathrm{CeO}_{2}(110)-\mathrm{Ov}$ structure and a relaxed/optimised defective $\mathrm{CeO}_{2}(110)-\mathrm{Ov}$ surface were used instead of the energy for the stoichiometric surface.
The charge density difference, $\rho_{\text {diff, }}$ was calculated by subtracting the sum of the charge densities of a $\mathrm{Cu}_{n}$ cluster $\left(\rho_{\mathrm{Cu}_{n}}\right)$ and the ceria surface $\left(\rho_{\text {ceria }}\right)$ of the same geometry as the system from the total charge density of the system $\left(\rho_{\text {sys }}\right)$, which is shown as follows.

$$
\rho_{\text {diff }}=\rho_{\text {sys }}-\left(\rho_{\mathrm{Cu}_{n}}+\rho_{\text {ceria }}\right)
$$

\section{Results and discussion}

\subsection{Adsorption of $\mathrm{Cu}$ on $\mathrm{CeO}_{2}(110)$ surface}

We first reproduced the atomic and electronic investigation of a $\mathrm{Cu}$ adatom adsorbed on $\mathrm{CeO}_{2}(110)$ at four different adsorption sites, $^{22}$ i.e. on top of a surface Ce atom (Ce $\mathrm{top}_{\text {top }}$, a surface $\mathrm{O}$ atom $\left(\mathrm{O}_{\mathrm{top}}\right)$, the middle of a surface four-fold hollow site

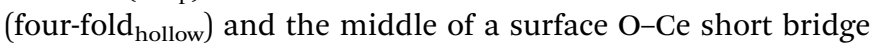
site $\left(\mathrm{O}-\mathrm{Ce}_{\text {short bdg }}\right)$. In the optimised structure having the most negative $\mathrm{Cu}$ adsorption energy of $-3.258 \mathrm{eV}$, the $\mathrm{Cu}$ atom is close to the surface and bonded with two surface $\mathrm{O}$ ions on top of a second-layer Ce ion (named as an $\mathrm{O}-\mathrm{Ce}-\mathrm{O}$ long bridge site), which agrees with earlier work. ${ }^{21,22}$ Results and detailed discussion can be found in ESI, $\dagger$ Section S1.1.

\subsection{Adsorption of $\mathrm{Cu}_{2}$ on $\mathrm{CeO}_{2}(110)$ surface}

$\mathrm{A} \mathrm{Cu}_{2}$ cluster with a $\mathrm{Cu}-\mathrm{Cu}$ distance of $2.42 \AA$ was placed either around an $\mathrm{O}-\mathrm{Ce}-\mathrm{O}$ long bridge site (Conf1-5) or on top of a second-layer four-fold hollow site (Conf6-7), parallel or perpendicular to the $\mathrm{CeO}_{2}(110)$ surface, producing seven initial structures, illustrated in Fig. 1. The $\mathrm{O}-\mathrm{Ce}-\mathrm{O}$ long bridge site was the most stable adsorption site, as found in Section 4.1, therefore, this site and the associated second-layer four-fold hollow site were chosen.

Local surface distortion around the $\mathrm{Cu}_{2}$ cluster is observed in all optimised structures (see Fig. 2), also indicated by the average surface $\mathrm{Ce}-\mathrm{O}$ bond lengths which are slightly larger than that of a pristine surface $(2.342 \AA)$, as listed in Table 1 . Only Conf4 and Conf7 show significant structural changes from their corresponding initial structures. For Conf4, the two $\mathrm{Cu}$ atoms are bonded with nearby surface $\mathrm{O}$ ions at two long bridge sites, respectively, which were initially placed at one long bridge site. The optimised structure of Conf7 is essentially the same as that of Conf 4 despite the $\mathrm{Cu}_{2}$ cluster being initially perpendicular to the surface, indicating that formation of a linear $\mathrm{Cu}_{2}$ cluster parallel and close to the surface is favoured. The optimised Conf7 has the most negative $\mathrm{Cu}$ adsorption energy, followed by Conf4, Conf1, Conf5, Conf3, Conf2 and Conf6. Therefore, only the most stable Conf7 and metastable Conf4 and 1 are discussed here.

Conf7, 4, and 1 have similar optimised structures, i.e. two $\mathrm{Cu}$ atoms bonded at two long bridge sites, ${ }^{23}$ in which the number of surface $\mathrm{O}$ ions available for $\mathrm{Cu}-\mathrm{O}$ binding is maximised, showing short $\mathrm{Cu}-\mathrm{O}$ distances in the range of 1.8-1.9 (see Table 1) and the most negative adsorption energies at $-3.492,-3.367$, and $-2.810 \mathrm{eV}$, respectively.

In terms of electronic structures, Conf7, 4, and 1 have two electrons transferred from the $\mathrm{Cu}_{2}$ cluster to the surface, illustrated by the spin density isosurfaces of two reduced $\mathrm{Ce}^{3+}$ 

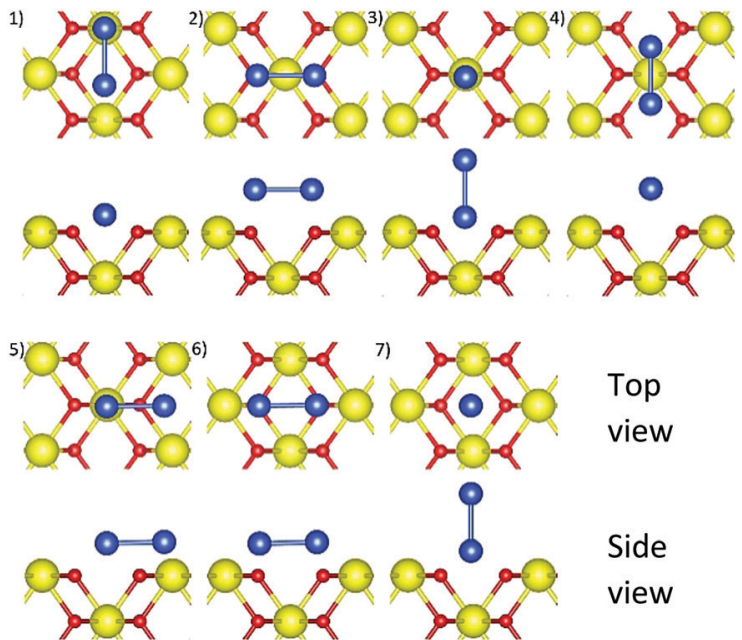

Fig. 1 Top view and side view of seven initial configurations of a $\mathrm{Cu}_{2}$ cluster placed at different adsorption sites on the $\mathrm{CeO}_{2}(110)$ surface, labelled as (1) to (7). Cerium, oxygen, and copper atoms are represented by red, yellow, and blue spheres respectively.

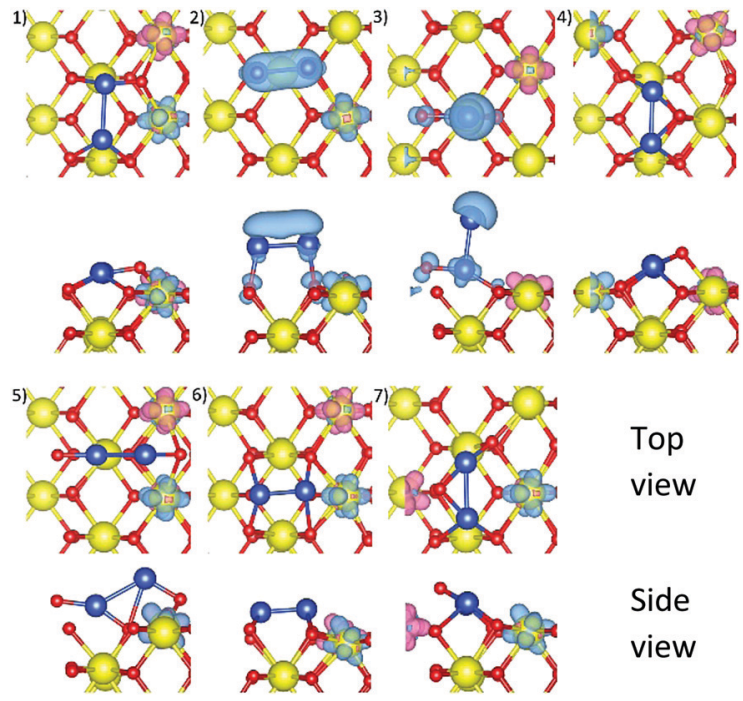

Fig. 2 Top view and side view of optimised $\mathrm{Cu}_{2} / \mathrm{CeO}_{2}(110)$ structures with spin density isosurfaces of 0.005 e $\AA^{-3}$ around $\mathrm{Cu}$ and reduced $\mathrm{Ce}^{3+}$ ions, labelled as (1) to (7). Blue: up spin; pink: down spin. ions, Fig. 2, also their distinct magnetic moments in opposite spins $\left(M_{\mathrm{Ce}}\right.$, Table 1$)$, and their $\mathrm{Cu}_{2}$ total magnetic moment being 0 .

Different $\mathrm{Ce}^{3+}$ localisation has an impact on the $\mathrm{Cu}$ adsorption energy of Conf7, 4 and 1 . In Conf7 and 4 , the two $\mathrm{Ce}^{3+}$ ions are located at two different surface four-fold hollow sites, opposite to each other, which enables nearby oxygen ions to bind strongly with the $\mathrm{Cu}$ atoms, thus stabilising the structure. Differently, in Conf1, the two $\mathrm{Ce}^{3+}$ ions are on the same four-fold hollow site. Since a $\mathrm{Ce}^{3+}$ ion has a larger radius than a $\mathrm{Ce}^{4+}$ ion, the two $\mathrm{Ce}^{3+}$ ions move slightly away from each other, stretching $\mathrm{Ce}-\mathrm{O}$ bonds and thus limiting movement of the bridging $\mathrm{O}$ ion towards its nearest $\mathrm{Cu}$ atom.

Besides, slightly different $\mathrm{Cu}-\mathrm{O}$ interactions of Conf7 and 4 also affects their adsorption energies, though they have similar geometry and $\mathrm{Ce}^{3+}$ localisation. A detailed PDOS analysis was conducted, focusing on orbital interactions between one of the $\mathrm{Cu}$ atoms and its bonded three $\mathrm{O}$ ions (labelled as $\mathrm{O} 1, \mathrm{O} 2, \mathrm{O} 3$, in ESI, $\dagger$ Fig. S7). Conf7 and 4 show similar overall signatures

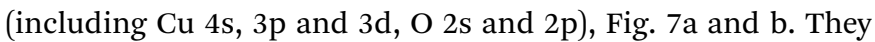
also demonstrate a noticeable overlap between $\mathrm{Cu} 3 \mathrm{~d}$ and $\mathrm{O} 2 \mathrm{p}$ orbitals in the range of -6 to $-5 \mathrm{eV}$, which is shown in more detail by PDOS plots of this $\mathrm{Cu}$ and its nearest $\mathrm{O}$ ion, ESI, $\dagger$ Fig. S7c and d. Additionally, a comparison of the $3 \mathrm{~d}$ signatures of the $\mathrm{Cu}_{2}$ cluster before (ESI, $\dagger$ Fig. S8a) and after adsorption shows that they are broader in Conf7 as compared to Conf4. Further to this the number of states of $\mathrm{O} 2 \mathrm{p}$ signature in the range of -2 to $0 \mathrm{eV}$ is larger in Conf7 than in Conf4, indicating stronger $\mathrm{Cu}-\mathrm{O}$ interactions, which suggests why Conf7 has a slightly more negative adsorption energy. The strong $\mathrm{Cu}-\mathrm{O}$ interactions are also confirmed by a deeper energy of $\mathrm{Cu} 3 \mathrm{~d}$ and $\mathrm{O} 2 \mathrm{p}$ orbitals in both configurations than that of $\mathrm{Cu} 3 \mathrm{~d}$ in a gaseous $\mathrm{Cu}_{2}$ cluster and $\mathrm{O} 2 \mathrm{p}$ on a pristine $\mathrm{CeO}_{2}(110)$ surface (see ESI, $\uparrow$ Fig. S8b).

For other configurations with less negative adsorption energies (see ESI, $\dagger$ Section S1.2), the observed weakening in adsorption energies of these configurations is seen to correlate with the decrease in $\mathrm{Cu}-\mathrm{Cu}$ bond lengths, suggestive of a Coulomb repulsion between $\mathrm{Cu}$ atoms in sterically constrained structures. Partial oxidation of $\mathrm{Cu}_{2}$ to a top $\mathrm{Cu}^{\delta-}$ and a bottom $\mathrm{Cu}^{2+}$ species (Conf3) or two $\mathrm{Cu}^{\delta+}$ (Conf2), and partial reduction of $\mathrm{Ce}^{4+}$ to $\mathrm{Ce}^{3+21}$ (Conf6), also suggest electronic structures affecting $\mathrm{Cu}$ adsorption energy.

Table $1 \mathrm{Cu}_{2} / \mathrm{CeO}_{2}(110)$ system: calculated magnetic moment of Cu clusters (s, p, d orbitals) and individual $\mathrm{Ce}^{3+}$ ions (s, p, d, forbitals) in Bohr magneton $\left(\mu_{\mathrm{B}}\right)$; number of $\mathrm{Ce} \mathrm{e}^{3+}$ ions; average $\mathrm{Cu}-\mathrm{O}$ bond length shown in Fig. $2(\AA)$; $\mathrm{Cu}-\mathrm{Cu}$ bond length $(\AA)$; average $\mathrm{Ce}-\mathrm{O}$ bond length $(\AA \AA)$ on the surface; adsorption energy per $\mathrm{Cu}$ atom (eV)

\begin{tabular}{|c|c|c|c|c|c|c|c|}
\hline System & $M_{\mathrm{Cu} \text { cluster }}\left(\mu_{\mathrm{B}}\right)$ & $\begin{array}{l}M_{\mathrm{Ce}} \\
\left(\mu_{\mathrm{B}}\right)\end{array}$ & $\begin{array}{l}\text { Number of } \\
\mathrm{Ce}^{3+} \text { reduced }\end{array}$ & $\mathrm{Cu}-\mathrm{O}(\AA)$ & $\mathrm{Cu}-\mathrm{Cu}(\AA)$ & $(\mathrm{Ce}-\mathrm{O})_{\text {surf }}(\AA)$ & $E_{\text {ad }}(\mathrm{eV})$ \\
\hline Conf1 & 0 & $0.941 /-0.969$ & 2 & 1.846 & 2.601 & 2.360 & -2.810 \\
\hline Conf2 & 0.329 & 0.966 & 1 & 1.834 & 2.268 & 2.349 & -1.725 \\
\hline Conf4 & 0 & $0.966 /-0.963$ & 2 & 1.904 & 2.411 & 2.342 & -3.367 \\
\hline Conf5 & 0 & $0.952 /-0.952$ & 2 & 1.936 & 2.512 & 2.367 & -2.163 \\
\hline Conf6 & 0.022 & $0.859 /-0.964$ & 2 & 2.033 & 2.175 & 2.369 & -0.973 \\
\hline
\end{tabular}


Overall, we find the configuration with the most negative adsorption energy showing two $\mathrm{Cu}$ adsorbed at two adjacent long bridge sites, and intriguingly complex electronic structures with varied interactions between $\mathrm{Cu}$ species and between $\mathrm{Cu}$ and surface ions at different positions.

\subsection{Adsorption of $\mathrm{Cu}_{3}$ on $\mathrm{CeO}_{2}(110)$ surface}

The two stable structures from the $\mathrm{Cu}_{2} / \mathrm{CeO}_{2}(110)$ system with small adjustments were used to construct eight initial $\mathrm{Cu}_{3} /$ $\mathrm{CeO}_{2}(110)$ configurations. The third $\mathrm{Cu}$ was placed at different adsorption sites on the surface with respect to the $\mathrm{Cu}_{2}$ cluster at different heights from the surface (Fig. 3).

All optimised structures show surface distortion around the $\mathrm{Cu}$ atoms, as illustrated in Fig. 4, also shown by the average surface $\mathrm{Ce}-\mathrm{O}$ bond lengths being larger than that of a pristine surface, as noted in Table 2. The optimised Conf3, 2, and 1 show a linear $\mathrm{Cu}_{3}$ structure ${ }^{23}$ and the most negative adsorption energies of $-3.429 \mathrm{eV},-3.318 \mathrm{eV}$, and $-3.307 \mathrm{eV}$, respectively. This is because the three $\mathrm{Cu}$ atoms are adsorbed at three adjacent long bridge sites, enabling them to bond strongly with at least two nearby surface $\mathrm{O}$ ions, showing short $\mathrm{Cu}-\mathrm{O}$ distances in the range of 1.75-1.90 $\AA$, Table 2, which agree with the calculated values reported by Chutia $e t$ al., yet smaller than their experimentally measured values of $1.9-2.4 \AA^{22} \mathrm{Cu}-\mathrm{Cu}$ interactions are weak since $\mathrm{Cu}$ atoms are far apart, hardly interacting, except in Conf3. This additional $\mathrm{Cu}-\mathrm{Cu}$ bond $(2.463 \AA)$ thus leads to the most negative $\mathrm{Cu}$ adsorption energy of Conf3.

We note that Ren et al. also calculated the adsorption energy per $\mathrm{Cu}$ atom of $\mathrm{a} \mathrm{Cu}_{3}$ linear cluster $(-1.69 \mathrm{eV})$ on $\mathrm{CeO}_{2}(110)$, which was greater than that of a $\mathrm{Cu}_{3}$ triangle cluster $(-1.53 \mathrm{eV})$; yet with a difference of more than $1 \mathrm{eV}$ in absolute values from ours, could that have resulted from different model parameters

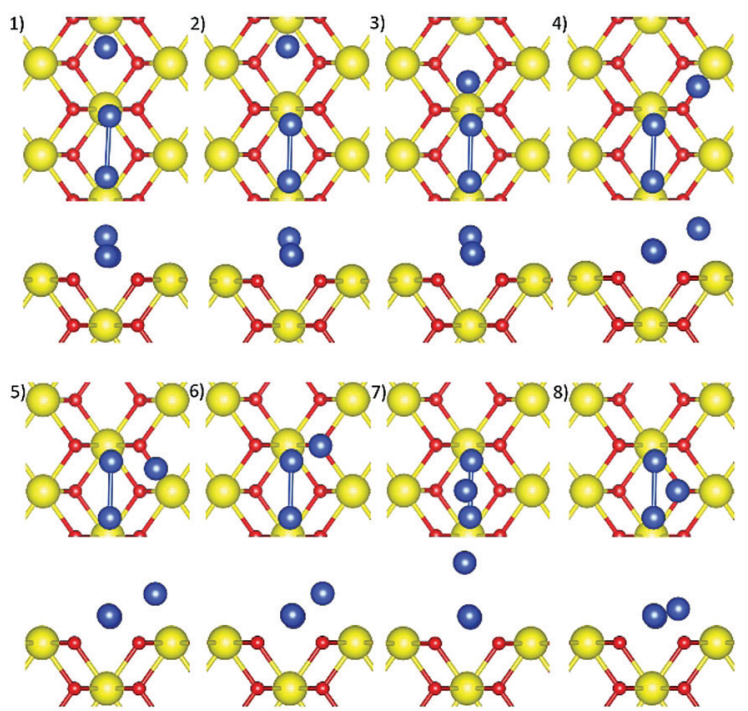

Fig. 3 Top and side view of eight initial configurations of a $\mathrm{Cu}_{3}$ cluster located at different adsorption sites on the $\mathrm{CeO}_{2}(110)$ surface, labelled as (1) to (8). The $\mathrm{Cu}_{2}$ clusters are emphasised by the $\mathrm{Cu}-\mathrm{Cu}$ bond.

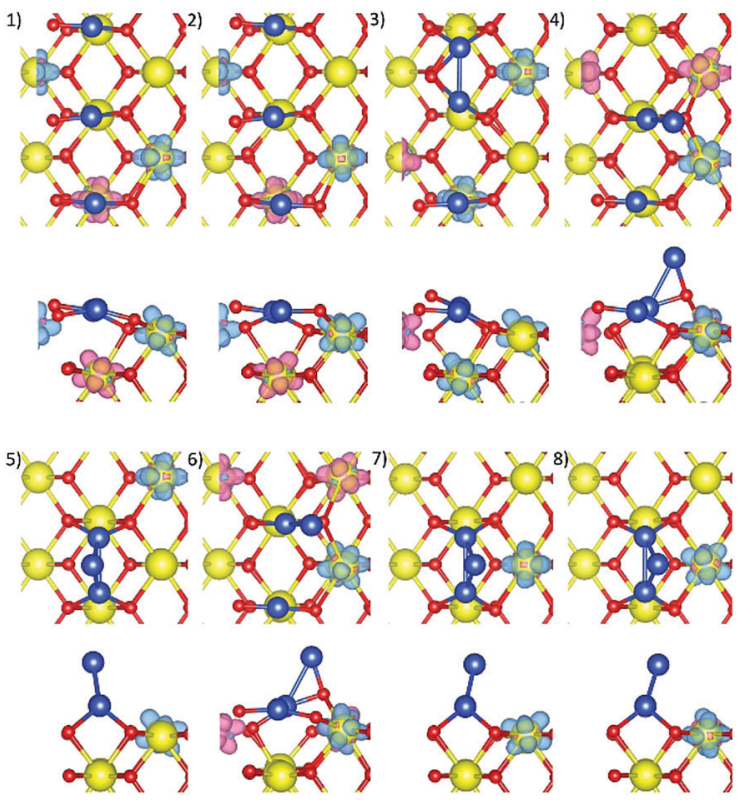

Fig. 4 Top view and side view of optimised $\mathrm{Cu}_{3} / \mathrm{CeO}_{2}(110)$ structures with spin density isosurfaces of $0.005 \mathrm{e}^{-3}$ around $\mathrm{Cu}$ and reduced $\mathrm{Ce}^{3+}$ ions, labelled as (1) to (8).

used, such as supercell size, cut-off energy, force convergence criteria, and $k$-point sampling. ${ }^{23}$

The most stable Conf3, and metastable Conf2 and 1, have three electrons transferred from $\mathrm{Cu}_{3}$ to the surface, as illustrated by the spin density isosurfaces around three reduced $\mathrm{Ce}^{3+}$ ions, Fig. 4 .

Other configurations have a $\mathrm{Cu}_{3}$ triangle adsorbed on the surface, thus resulting in weak copper-surface oxygen interactions, and weak electronic interactions (see ESI, $\uparrow$ Section S1.3), and consequently less negative adsorption energies.

The $\mathrm{Cu}_{1-3} / \mathrm{CeO}_{2}(110)$ configurations with the most negative $\mathrm{Cu}$ adsorption energies suggest that, with an increasing $\mathrm{Cu}$ loading, a Cu monolayer grows along the long bridge sites upon $\mathrm{Cu}$ adsorption, demonstrated by a $\mathrm{Cu}$ adatom growing to a $\mathrm{Cu}_{2}$, and a linear $\mathrm{Cu}_{3}$ cluster at the long bridge sites, agreeing with previous work. ${ }^{23}$ Our extensive examination of different initial configurations of $\mathrm{Cu}_{n}$ adsorbed at various adsorption sites, and associated detailed electronic structure investigation, provide insights into the impact of surface $\mathrm{Cu}-\mathrm{O}$ and $\mathrm{Cu}-\mathrm{Cu}$ interactions on optimised structures and adsorption energies.

\subsection{Adsorption of $\mathrm{Cu}_{4}$ on $\mathrm{CeO}_{2}(110)$ surface}

Eight initial structures were constructed based on a stable linear $\mathrm{Cu}_{3}$ cluster and a triangular cluster from the $\mathrm{Cu}_{3} /$ $\mathrm{CeO}_{2}(110)$ system. The fourth $\mathrm{Cu}$ atom was placed at different adsorption sites with respect to the $\mathrm{Cu}_{3}$ cluster and at different heights above the surface, Fig. 5.

All optimised structures show surface distortion around the $\mathrm{Cu}$ atoms, as illustrated in Fig. 6, also shown by the different values of average surface $\mathrm{Ce}-\mathrm{O}$ bond length from that of a pristine surface, as listed in Table 3. Conf3, 4, and 1 have the most negative $\mathrm{Cu}$ adsorption energies at $-2.971,-2.961$, and 
Table $2 \mathrm{Cu}_{3} / \mathrm{CeO}_{2}(110)$ system: calculated magnetic moment of Cu clusters (s, p, d orbitals) and individual Ce ${ }^{3+}$ ions (s, p, d, forbitals) in Bohr magneton $\left(\mu_{\mathrm{B}}\right)$; number of $\mathrm{C} \mathrm{e}^{3+}$ ions; average $\mathrm{Cu}-\mathrm{O}$ bond length shown in Fig. $8(\AA)$; average $\mathrm{Cu}-\mathrm{Cu}$ bond length $(\AA)$; average $\mathrm{Ce}-\mathrm{O}$ bond length $(\AA)$ on the surface; adsorption energy per $\mathrm{Cu}$ atom (eV)

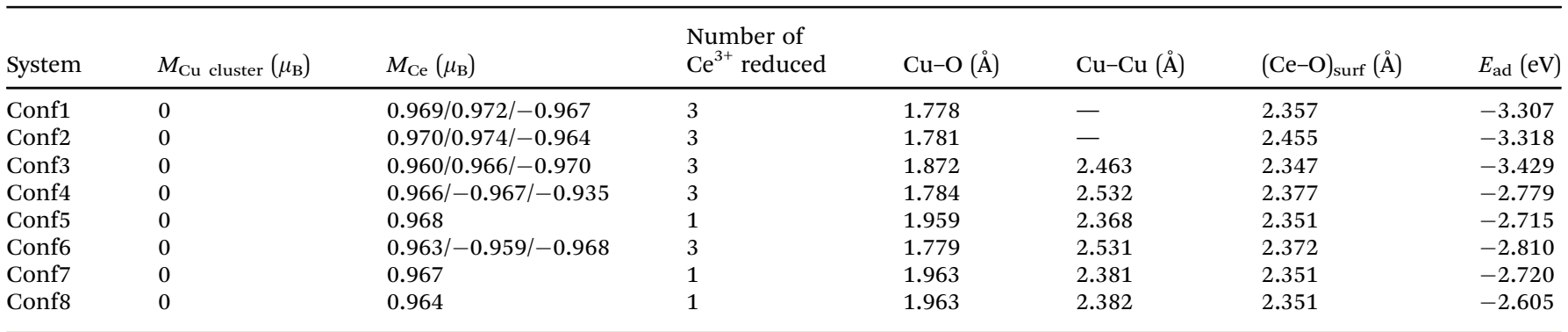

$-2.918 \mathrm{eV}$, respectively, followed by Conf2, Conf7, Conf8, Conf6 and Conf5, Table 3. Therefore, only the former three are discussed here (see ESI, $\uparrow$ Section S1.4 for more details).

In Conf3 and 4, there is an isolated $\mathrm{Cu}$ bonded at a long

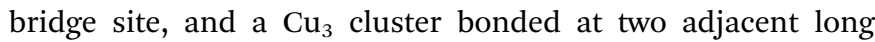
bridge sites. In Conf3, the fourth $\mathrm{Cu}$ is raised above the surface to bond with two $\mathrm{Cu}$ and one $\mathrm{O}$ ion, while in Conf4, the fourth $\mathrm{Cu}$ atom moves down slightly towards the surface, bonding with one second-layer and one surface $\mathrm{O}$ ion, and two nearest $\mathrm{Cu}$ atoms. In Conf1, the four $\mathrm{Cu}$ atoms are distributed at three adjacent long bridge sites, i.e. two isolated $\mathrm{Cu}$ at two long bridge sites, and a $\mathrm{Cu}_{2}$ cluster at one long bridge site. The fourth $\mathrm{Cu}$ atom moves from the $\mathrm{Ce}_{\text {top }}$ site towards and bonds with the nearest surface $\mathrm{O}$ ion and one nearby $\mathrm{Cu}$. The strong copper-surface interactions in Conf3, 4, and 1 thus contribute to their most negative adsorption energies.

From a $\mathrm{Cu}_{3}$ to a $\mathrm{Cu}_{4}$ cluster, the close competition between $\mathrm{Cu}-\mathrm{O}$ and $\mathrm{Cu}-\mathrm{Cu}$ interactions within a limited space leads to a $\mathrm{Cu}$ monolayer to bilayer transition along the adjacent long bridge sites. The small energy difference between Conf3, 4,1 ,

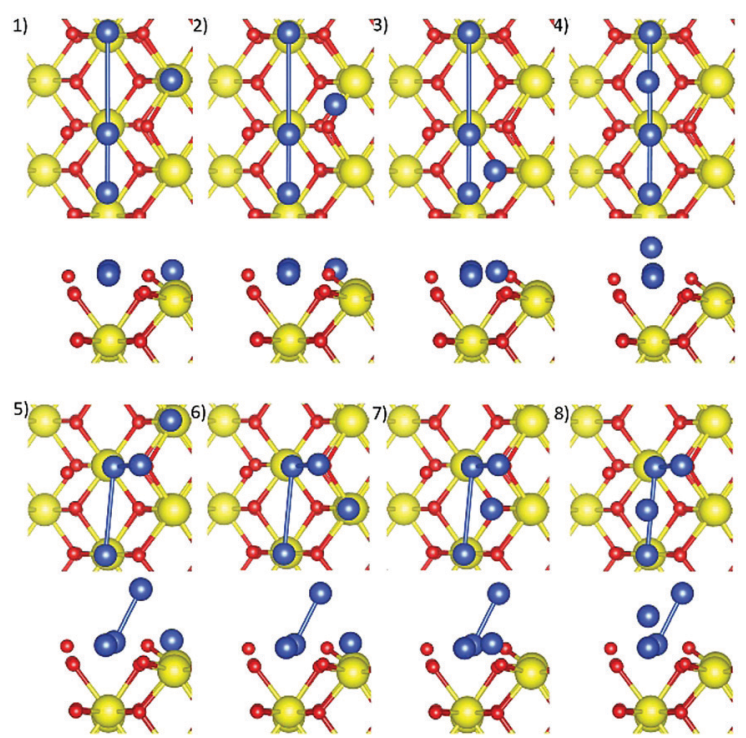

Fig. 5 Top view and side view of eight initial configurations of a $\mathrm{Cu}_{4}$ cluster located at different adsorption sites on the $\mathrm{CeO}_{2}(110)$ surface, labelled as (1) to (8). The $\mathrm{Cu}_{3}$ clusters are emphasised by the $\mathrm{Cu}-\mathrm{Cu}$ bonds which may not physically exist. and 2 (maximum of $0.11 \mathrm{eV}$ ) and their different structures suggest that a $\mathrm{Cu}$ bilayer can start growing from several configurations. The stable and especially interesting optimised structure of Conf4, with one of the $\mathrm{Cu}$ atoms incorporated into the surface, is also observed experimentally. ${ }^{19,43}$

Conf2 has an adsorption energy very close to Con1, yet, it only has three electrons transferred, showing interesting electronic features in relevance to catalytic reactions. Its $\mathrm{Cu}$ $4 \mathrm{~s}$ orbital PDOS plots, ESI, $\dagger$ Fig. S14a-c, suggest that the bottom three $\mathrm{Cu}$ atoms each donate one electron to the surface, becoming a $\mathrm{Cu}^{+}$ion. Interestingly, the top $\mathrm{Cu}$ has two $4 \mathrm{~s}$ electrons in opposite spins (a pair of distinct 4s signatures below $E_{\mathrm{F}}$ ), forming a $\mathrm{Cu}^{\delta-}$ species with a Bader charge of $-0.437 e$. This extra electron appearing in the top $\mathrm{Cu} 4 \mathrm{~s}$ orbital originates from the bottom two $\mathrm{Cu}$ atoms with spin density isosurfaces, Fig. 6 . In the plots of their $3 \mathrm{~d}$ orbital PDOS, ESI, $\dagger$ Fig. S15, we note each has one unoccupied down-spin signature
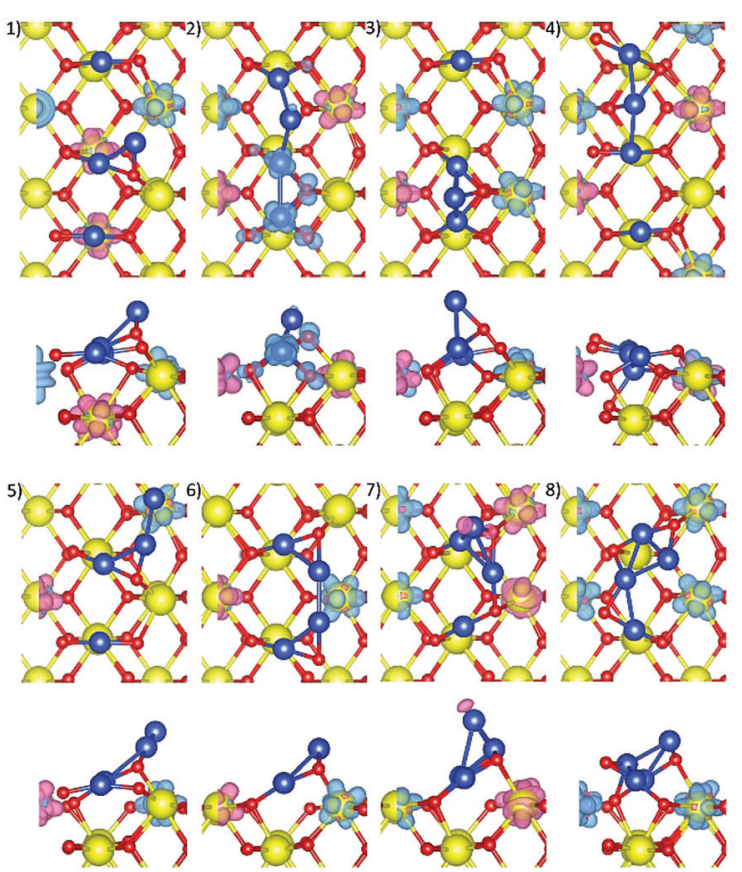

Fig. 6 Top view and side view of optimised $\mathrm{Cu}_{4} / \mathrm{CeO}_{2}(110)$ structures with the spin density isosurfaces of 0.005 e $\AA^{-3}$ around $\mathrm{Cu}$ and reduced $\mathrm{Ce}^{3+}$ ions, labelled as (1) to (8). 
Table $3 \mathrm{Cu}_{4} / \mathrm{CeO}_{2}(110)$ system: calculated magnetic moment of $\mathrm{Cu}$ clusters (s, $p, d$ orbitals), of all $\mathrm{Ce}^{3+}$ ions and individual $\mathrm{Ce}{ }^{3+}$ ions (s, $p, d, f$ orbitals) in Bohr magneton $\left(\mu_{\mathrm{B}}\right)$; number of $\mathrm{Ce}^{3+}$ ions; average $\mathrm{Cu}-\mathrm{O}$ bond length shown in Fig. $11(\AA)$; average $\mathrm{Cu}-\mathrm{Cu}$ bond length $(\AA)$; average $\mathrm{Ce}-\mathrm{O}$ bond length (Å) on the surface; adsorption energy per $\mathrm{Cu}$ atom (eV)

\begin{tabular}{|c|c|c|c|c|c|c|c|c|}
\hline System & $M_{\mathrm{Cu} \text { cluster }}\left(\mu_{\mathrm{B}}\right)$ & $M_{\text {Ce-total }}\left(\mu_{\mathrm{B}}\right)$ & $M_{\mathrm{Ce}}\left(\mu_{\mathrm{B}}\right)$ & Number of $\mathrm{Ce}^{3+}$ reduced & $\mathrm{Cu}-\mathrm{O}(\AA)$ & $\mathrm{Cu}-\mathrm{Cu}(\AA)$ & $(\mathrm{Ce}-\mathrm{O})_{\text {surf }}(\AA)$ & $E_{\text {ad }}(\mathrm{eV})$ \\
\hline Conf1 & 0.006 & -0.009 & $0.958 / 0.952 /-0.961 /-0.958$ & 4 & 1.790 & 2.516 & 2.346 & -2.918 \\
\hline Conf2 & 0.577 & -0.954 & $0.967 /-0.967 /-0.954$ & 3 & 1.894 & 2.428 & 2.352 & -2.859 \\
\hline Conf3 & -0.007 & 1.925 & $0.945 / 0.966 / 0.965 /-0.951$ & 4 & 1.868 & 2.495 & 2.369 & -2.971 \\
\hline Conf4 & 0 & 0.009 & $0.970 / 0.968 /-0.964 /-0.965$ & 4 & 1.844 & 2.417 & 2.364 & -2.961 \\
\hline Conf4-2 & 0.303 & -0.941 & $0.970 /-0.949 /-0.962$ & 3 & 1.914 & 2.361 & 2.353 & -2.840 \\
\hline Conf5 & 0 & 0 & $0.964 /-0.968$ & 2 & 1.785 & 2.441 & 2.338 & -2.470 \\
\hline Conf6 & -0.041 & -0.020 & $0.949 /-0.969$ & 2 & 1.851 & 2.488 & 2.334 & -2.752 \\
\hline Conf7 & -0.064 & 0.210 & $-0.755 / 0.970 / 0.966 / 0.969$ & 4 & 1.828 & 2.560 & 2.361 & -2.806 \\
\hline Conf8 & 0 & 0.008 & $0.957 / 0.957 /-0.942 /-0.964$ & 4 & 1.860 & 2.410 & 2.356 & -2.792 \\
\hline
\end{tabular}

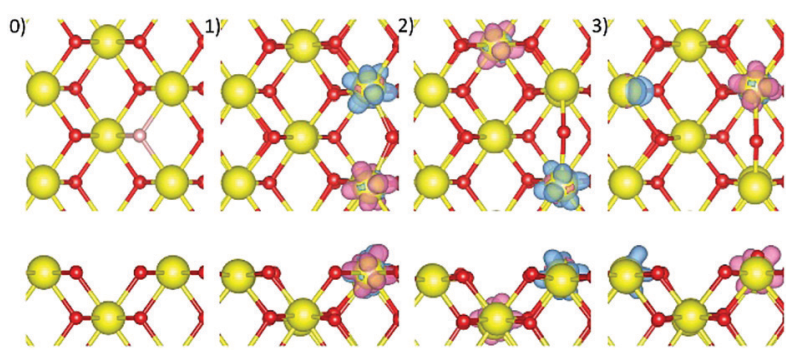

Fig. 7 Top view and side view of (0) an initial structure of $\mathrm{CeO}_{2}(110)-\mathrm{OV}$ surface (the removed oxygen atom is highlighted using a light pink sphere); (1-3) three optimised $\mathrm{CeO}_{2}(110)$ surface structures with spin density isosurfaces of 0.005 e $\AA^{-3}$ around reduced $\mathrm{Ce}^{3+}$ ions which are located at different positions on the surface.

above $E_{\mathrm{F}}$, suggesting the electron in the top $\mathrm{Cu}$ is partially from these two bottom $\mathrm{Cu} 3 \mathrm{~d}$ orbitals, though the contribution from the bottom $\mathrm{Cu}$ furthest away from the top is larger. Since this $\mathrm{Cu}$ is coordinated with three $\mathrm{O}$ ions, it can be easily stabilised as a $\mathrm{Cu}^{2+}$ ion, with a Bader charge of $0.724 e e^{21}$ As Conf2 and 3 have similar energies, electrons can easily exchange between $\mathrm{Cu}$ ions on $\mathrm{CeO}_{2}(110)$, i.e. shift between $\mathrm{Cu}^{+}$and $\mathrm{Cu}^{2+}$, which has been reported as providing active sites for many reactions. ${ }^{6,10,17}$

Paz-Borbón et al. showed a maximum of two electrons transferred from a $\mathrm{Cu}_{4}$ cluster to $\mathrm{CeO}_{2}(111),{ }^{15}$ whereas in our study, 2-4 electrons are transferred to $\mathrm{CeO}_{2}(110)$. This significant difference in the number of electrons transferred suggests $\mathrm{CeO}_{2}(110)$ could be more easily reduced after $\mathrm{Cu}$ cluster adsorption.

To investigate other additional possible electron transfers from $\mathrm{Cu}_{4}$ to $\mathrm{CeO}_{2}(110)$, the initial structure of Conf4 was used to set up new structures, in which 1-3 pre-assumed $\mathrm{Ce}^{3+}$ ions were replaced with 1-3 La ions, respectively, for geometry optimisation. These La ions were then replaced by Ce ions for final optimisation. It was only possible to observe three electrons transferred, in one structure (labelled as Conf4-2, detailed discussion in ESI, $\dagger$ Section S1.4), whereas in the other two, four electrons were still transferred.

From the above discussion, we can conclude that $\mathrm{CeO}_{2}(110)$ is highly reducible upon $\mathrm{Cu}_{4}$ adsorption, and competing $\mathrm{Cu}-\mathrm{Cu}$ and $\mathrm{Cu}-\mathrm{O}$ interactions are important in determining $\mathrm{Cu}_{4}$ shape and energetics, and electronic structure of $\mathrm{Cu}_{4} / \mathrm{CeO}_{2}(110)$. Long-bridge site $\mathrm{Cu}$ atoms were the anchoring sites for $\mathrm{Cu}_{3}$ growth to $\mathrm{Cu}_{4}$.

\subsection{Adsorption of $\mathrm{Cu}$ and $\mathrm{Cu}_{2}$ on $\mathrm{CeO}_{2}(110)$ surface with one oxygen vacancy}

$\mathrm{CeO}_{2}(110)$ with one oxygen vacancy. To investigate the impact of surface oxygen vacancies on geometric and electronic properties of a $\mathrm{Cu}_{n} / \mathrm{CeO}_{2}(110)(n=1-4)$ structure, and on $\mathrm{Cu}-\mathrm{O}$ and $\mathrm{Cu}-\mathrm{Cu}$ interactions, we removed the same topmost-layer oxygen from different $\mathrm{Cu}_{n} / \mathrm{CeO}_{2}(110)$ initial structures before geometric and electronic optimisation.

An optimised defective $\mathrm{CeO}_{2}(110)$ surface with one surface oxygen vacancy $\left(\mathrm{CeO}_{2}(110)-\mathrm{Ov}\right)$ is chosen as the new baseline for adsorption energy calculations when absorbing different $\mathrm{Cu}$ clusters on such a defective surface.

We thus first removed one oxygen from $\mathrm{CeO}_{2}(110)$ (see Fig. 7(0)) and set up three configurations with different combinations of two pre-assumed $\mathrm{Ce}^{3+}$ sites around the oxygen vacancy, which are clearly illustrated in the optimised structures, Fig. 7(1-3). In Case1, the two surface $\mathrm{Ce}^{3+}$ ions are nearest neighbours (NN) of the vacancy. In Case2, one $\mathrm{Ce}^{3+}$ is a surface $\mathrm{NN}$, while the other is a second-layer next nearest neighbour (NNN) of the vacancy. In Case3, one $\mathrm{Ce}^{3+}$ is a surface $\mathrm{NN}$, while the other one is a surface NNN.

In Case1, the nearest surface oxygen ion moved towards the vacancy on the surface plane. It bonds with two $\mathrm{Ce}^{3+}$ ions with equal $\mathrm{Ce}^{3+}-\mathrm{O}$ bond lengths $(2.341 \AA$ ). There is no significant surface distortion, as indicated by an average surface $\mathrm{Ce}-\mathrm{O}$ distance of $2.381 \AA$, closest to the value of a stoichiometric surface, unlike in the other two cases, possibly because of the hindrance to relaxation of two adjacent large $\mathrm{Ce}^{3+}$ ions locally. ${ }^{24}$ In Case2, the nearest oxygen ion moves towards the vacancy significantly. It is slightly raised from the surface, bridging one $\mathrm{Ce}^{3+}$ and one $\mathrm{Ce}^{4+}$ ion. Since a $\mathrm{Ce}^{3+}$ ion has a larger radius than a $\mathrm{Ce}^{4+}$ ion, the $\mathrm{Ce}^{3+}-\mathrm{O}$ bond is longer than the $\mathrm{Ce}^{4+}-\mathrm{O}$ bond, forming an asymmetric bridge site. ${ }^{24} \mathrm{~A}$ similar asymmetric bridge site is also observed in Case3.

Calculated oxygen vacancy formation energies are in the range of $0.98-1.43 \mathrm{eV}$, as reported in Table 4 , which are slightly lower than those from previous work (1.54-2.69 eV), ${ }^{2,24,44-46}$ because of a more negative $\mathrm{O}_{2}$ binding energy of $-9.863 \mathrm{eV}$ (bond length $1.233 \AA$ ) used in our work ${ }^{24,47}$ (ESI, $\dagger$ Section S1.5). 
Table $4 \mathrm{CeO}_{2}(110)-O v$ system: calculated magnetic moment of individual $\mathrm{Ce}^{3+}$ ions (s, p, d, f orbitals) in Bohr magneton $\left(\mu_{\mathrm{B}}\right)$; number of $\mathrm{Ce}^{3+}$ ions reduced; average $\mathrm{Ce}-\mathrm{O}$ bond length $(\AA)$ on the surface and in the two sublayers, as shown in Fig. 7; oxygen vacancy formation energy (eV)

\begin{tabular}{llllll}
\hline System & $M_{\mathrm{Ce}}\left(\mu_{\mathrm{B}}\right)$ & $\begin{array}{l}\text { Number of } \\
\mathrm{Ce}^{3+} \text { reduced }\end{array}$ & $\begin{array}{l}(\mathrm{Ce}-\mathrm{O})_{\text {surf }} \\
(\AA)\end{array}$ & $\begin{array}{l}(\mathrm{Ce}-\mathrm{O})_{\text {sub }} \\
(\AA)\end{array}$ & $E_{v}(\mathrm{eV})$ \\
\hline Case1 & $0.969 /-0.973$ & 2 & 2.338 & 2.381 & 1.110 \\
Case2 & $0.962 /-0.899$ & 2 & 2.329 & 2.374 & 1.426 \\
Case3 & $-0.966 / 0.946$ & 2 & 2.333 & 2.373 & 0.978 \\
\hline \hline
\end{tabular}

The well-known error of overbinding $\mathrm{O}_{2}$ using GGA/LDA DFT and PAW potentials, ${ }^{24,46}$ as well as different computational parameters used (e.g. supercell size, cut-off energy, $U$ value, etc.) make it difficult to compare absolute values with earlier work; however the relative comparison between Case 1 to 3 is not affected. Case 3 shows the smallest oxygen vacancy formation energy, followed by Case 1 and 2, which suggests it is energetically favourable to form surface rather than secondlayer $\mathrm{Ce}^{3+}$ ions. $^{24,46} \mathrm{An} \mathrm{NN}-\mathrm{NNN} \mathrm{Ce}{ }^{3+}$ pair combination (Conf3) is more stable than a NN-NN combination (Conf1), suggesting it is favourable to coordinate a $\mathrm{Ce}^{3+}$ ion with $\mathrm{Ce}^{4+}$ ions rather than $\mathrm{Ce}^{3+}$ ions. $^{24}$ Therefore, Case 3 is chosen as the new baseline for $\mathrm{Cu}$ adsorption energy calculations.

$\mathrm{Cu} / \mathrm{CeO}_{2}(110)$ with one oxygen vacancy. The initial structure of $\mathrm{O}_{\text {top }}$ was chosen and the surface oxygen on the topmost layer directly under the $\mathrm{Cu}$ adatom was removed (see Fig. 8(0)). Two cases were set up with different locations of three pre-assumed $\mathrm{Ce}^{3+}$ ions.

Case 1 and 2 show similar optimised structures, in which the $\mathrm{Cu}$ atom is located at a long bridge site, bonding with two surface $\mathrm{O}$ ions, as illustrated in Fig. 8. These two structures are similar to the optimised $\mathrm{O}_{\text {top }}$ structure, as shown in ESI, $\dagger$ Fig. S2.2. Because of the additional $\mathrm{Cu}-\mathrm{O}$ interaction, the nearest surface $\mathrm{O}$ ion moved even closer to the vacancy and formed a $\mathrm{Cu}-\mathrm{O}$ bond, compared to that in a defective $\mathrm{CeO}_{2}(110)$ surface without $\mathrm{Cu}$ adsorption.

In both cases, there are three electrons trapped in three $\mathrm{Ce}^{3+}$ uf orbitals, i.e. one from the $\mathrm{Cu}$ adatom, and two from the oxygen vacancy. However, their electronic structures are quite different. In Case1, there is one surface and one second-layer

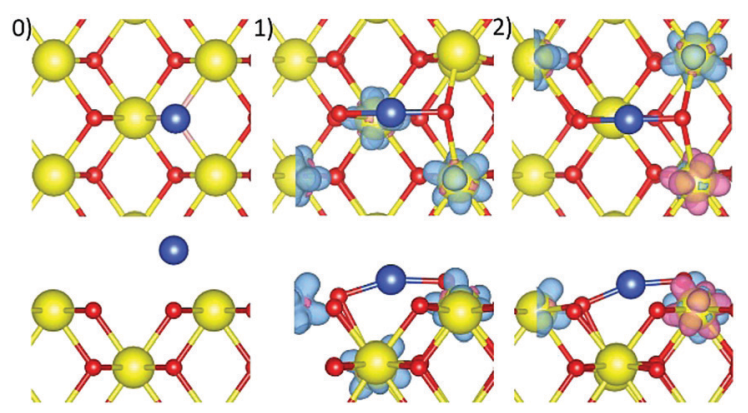

Fig. 8 Top view and side view of $(0)$ the initial structure of the $O_{\text {top }}$ configuration from the $\mathrm{Cu} / \mathrm{CeO}_{2}(110)$ system with one oxygen vacancy; $(1-2)$ two optimised structures with spin density isosurfaces of 0.005 e $\AA^{-3}$ around reduced $\mathrm{Ce}^{3+}$ ions which are located at different positions on the surface.
$\mathrm{NN} \mathrm{Ce}^{3+}$ of the vacancy, and one surface $\mathrm{NNN} \mathrm{Ce}^{3+}$. In Case2,

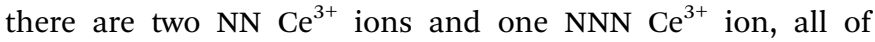
which are on the surface. Case 2 has a slightly more negative adsorption energy at $-3.690 \mathrm{eV}$, since it is energetically more favourable to form surface $\mathrm{Ce}^{3+}$ ions than second-layer $\mathrm{Ce}^{3+}$ ions. The shorter $\mathrm{Cu}-\mathrm{O}$ distance of Case 2 also contributes to its higher stability. Electron transfer is also confirmed by magnetic moments of these species, as listed in Table 5.

$\mathrm{Cu}_{2} / \mathrm{CeO}_{2}$ (110) with one oxygen vacancy. The initial structure of Conf1 and 4 from the $\mathrm{Cu}_{2} / \mathrm{CeO}_{2}(110)$ system were chosen to create one surface oxygen vacancy, respectively, seen in Fig. 9, since optimised Conf1 and 4 have the most negative $\mathrm{Cu}$ adsorption energies.

In optimised Conf1v and $4 \mathrm{v}$, shown in Fig. 9, the nearest surface oxygen ion moved very close to the vacancy, bonding to one of the $\mathrm{Cu}$ atoms. These two structures are very similar to the optimised Conf1 and 4 with a stoichiometric surface, although the $\mathrm{Cu}_{2}$ cluster bonds with the nearest oxygen ion of the vacancy instead of the oxygen ion originally at the vacancy.

Both Conf1v and $4 \mathrm{v}$ have four electrons localised at four $\mathrm{Ce}^{3+}$ ions. In Conf1v, all four $\mathrm{Ce}^{3+}$ ions are on the surface, i.e. two NNs and two NNNs of the vacancy. In Conf4v, there are two surface NNs, one second-layer NN, and one second-layer NNN, which introduces more structural perturbation to the surface, as suggested by a much smaller value of average surface Ce-O bond length $(2.317 \AA)$, compared to that of Conf1v (2.360 ̊). As a result, Conf1v shows a more negative $\mathrm{Cu}$ adsorption energy of $-3.356 \mathrm{eV}$ than Conf4v $(-3.207 \mathrm{eV})$. The stronger $\mathrm{Cu}-\mathrm{O}$ bonding with a shorter $\mathrm{Cu}-\mathrm{O}$ distance also contributes to the more negative adsorption energy of Conf1v. Electron transfer is also confirmed by the magnetic moments of these species, reported in Table 5 .

\subsection{Adsorption of $\mathrm{Cu}_{3}$ on $\mathrm{CeO}_{2}(110)$ surface with one oxygen vacancy}

The initial structure of Conf2, 3, 6 and 7 from the $\mathrm{Cu}_{3} /$ $\mathrm{CeO}_{2}(110)$ system were chosen to create one surface oxygen vacancy (see Fig. 10), whose optimised structures show stable linear $\mathrm{Cu}_{3}$ clusters and two types of unstable triangular $\mathrm{Cu}_{3}$ clusters, respectively.

Conf2v has the most negative $\mathrm{Cu}$ adsorption energy of $-3.350 \mathrm{eV}$, because of strong $\mathrm{Cu}-\mathrm{O}$ interactions. It is the only optimised structure showing a linear $\mathrm{Cu}_{3}$ cluster (see Fig. 10), similar to that of Conf2 with a stoichiometric surface. Surface oxygen ions on the same side as the vacancy are raised from the surface and bond closely with the $\mathrm{Cu}_{3}$ cluster, showing short $\mathrm{Cu}-\mathrm{O}$ distances (Table 6), which include the nearest surface oxygen ion which moves close to the vacancy. Conf7v, 6v, and $3 \mathrm{v}$ have weaker $\mathrm{Cu}$ adsorption, showing one $\mathrm{Cu}$ far away from the surface, without $\mathrm{Cu}$-surface $\mathrm{O}$ binding, as a result of weakened $\mathrm{Cu}-\mathrm{O}$ interactions due to vacancy formation (ESI, $\dagger$ Section S1.6).

In Conf $2 \mathrm{v}$, there are five electrons trapped in $\mathrm{Ce}^{3+} 4 \mathrm{f}$ orbitals, whereas in Conf $3 \mathrm{v}, 6 \mathrm{v}$ and $7 \mathrm{v}$, only three electrons are trapped, and the other two electrons are found to locate in the $\mathrm{Cu}_{3}$ cluster (discussion in ESI, $\dagger$ Section S1.6). 
Table $5 \mathrm{Cu} / \mathrm{CeO}_{2}(110)-\mathrm{Ov}$ system (Case1, 2) and $\mathrm{Cu}_{2} / \mathrm{CeO}_{2}(110)-O v$ system (Conf1v, 4v): calculated total magnetic moment of the optimised structures and that of individual $\mathrm{Ce}^{3+}$ ions (s, p, d, forbitals) in Bohr magneton $\left(\mu_{\mathrm{B}}\right)$; number of $\mathrm{Ce}^{3+}$ ions reduced; average $\mathrm{Cu}-\mathrm{O}$ bond length shown in Fig. 8 and 9, respectively ( $(\AA)$; average $\mathrm{Ce}-\mathrm{O}$ bond length ( $(\AA)$ on the surface; adsorption energy per $\mathrm{Cu}$ atom (eV)

\begin{tabular}{|c|c|c|c|c|c|c|c|}
\hline System & $M_{\text {total }}\left(\mu_{\mathrm{B}}\right)$ & $M_{\mathrm{Ce}}\left(\mu_{\mathrm{B}}\right)$ & Number of $\mathrm{Ce}^{3+}$ reduced & $\mathrm{Cu}-\mathrm{O}(\AA)$ & $\mathrm{Cu}-\mathrm{Cu}(\AA)$ & $(\mathrm{Ce}-\mathrm{O})_{\text {surf }}(\AA)$ & $E_{\text {ad }}(\mathrm{eV})$ \\
\hline Case1 & 2.896 & $0.969 / 0.955 / 0.973$ & 3 & 1.818 & - & 2.343 & -3.595 \\
\hline Case2 & 0.974 & $0.969 / 0.972 /-0.967$ & 3 & 1.809 & - & 2.349 & -3.690 \\
\hline Conf1v & -1.937 & $-0.975 /-0.971 / 0.967 /-0.960$ & 4 & 1.793 & - & 2.360 & -3.356 \\
\hline Conf4v & -1.929 & $-0.972 /-0.971 /-0.950 / 0.963$ & 4 & 1.908 & 2.479 & 2.317 & -3.207 \\
\hline
\end{tabular}

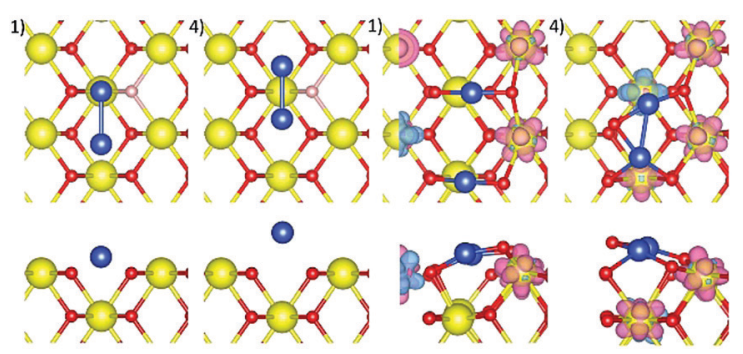

Fig. 9 Top view and side view of left (1) and (4): the initial structure of Conf1v and $4 \mathrm{v}$, respectively, from the $\mathrm{Cu}_{2} / \mathrm{CeO}_{2}(110)$ system with one oxygen vacancy; right (1) and (4) the corresponding optimised structures of Conf1v and $4 v$ with spin density isosurfaces of 0.005 e $\AA^{-3}$ around $\mathrm{Cu}$ and reduced $\mathrm{Ce}^{3+}$ ions

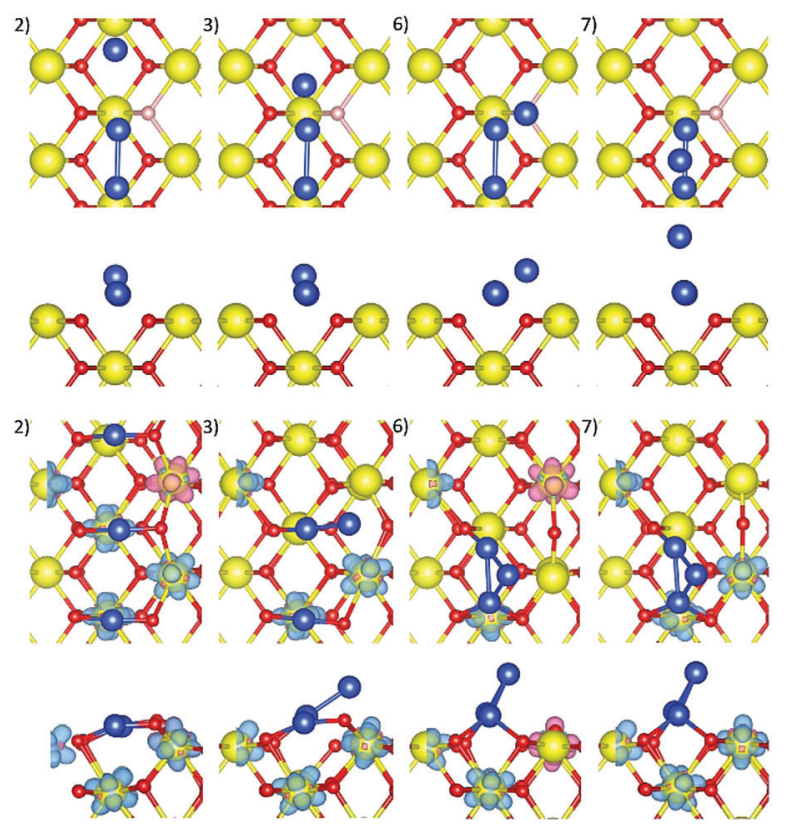

Fig. 10 Top row: Top view and side view of initial structures of Conf1v, 2v $6 v$ and $7 v$, respectively, from the $\mathrm{Cu}_{3} / \mathrm{CeO}_{2}(110)$ system with one oxygen vacancy. The $\mathrm{Cu}_{2}$ clusters are emphasised by the $\mathrm{Cu}-\mathrm{Cu}$ bond. Bottom row: Top view and side view of the corresponding optimised structures of Conf1 $1 v, 2 v, 6 v$ and $7 v$, respectively, with spin density isosurfaces of 0.005 e $\AA^{-3}$ around $\mathrm{Cu}$ and reduced $\mathrm{Ce}^{3+}$ ions.

From the $\mathrm{Cu}_{1-3} / \mathrm{CeO}_{2}(110)-\mathrm{Ov}$ configurations with the most negative $\mathrm{Cu}$ adsorption energies, we could again conclude a $\mathrm{Cu}$ monolayer growth pattern along the long bridge sites after $\mathrm{Cu}$ adsorption, which is essentially the same as that on a stoichiometric surface. Both surface and second-layer $\mathrm{Ce}^{3+}$ ions are formed, but the latter are energetically less favoured.

\subsection{Adsorption of $\mathrm{Cu}_{4}$ on $\mathrm{CeO}_{2}(110)$ surface with one oxygen vacancy}

The initial structures of Conf2, 3, 4, and 7 from the $\mathrm{Cu}_{4} / \mathrm{CeO}_{2}(110)$ system were chosen to create one surface oxygen vacancy, Fig. 11, whose optimised structures demonstrate unique features and represent both stable and unstable configurations.

Conf $4 \mathrm{v}$ has the most negative $\mathrm{Cu}$ adsorption energy of $-2.674 \mathrm{eV}$, tightly followed by Conf3v, Conf7v, and Conf2v, Table 6, whose geometric and electronic structures discussed in detail in ESI, $\uparrow$ Section S1.7. The optimised Conf4v is different from Conf4 with a stoichiometric surface, as a result of weakened $\mathrm{Cu}-\mathrm{O}$ interactions. The fourth $\mathrm{Cu}$ in Conf $4 \mathrm{v}$ moves away from the surface and bonds with two $\mathrm{Cu}$ and one $\mathrm{O}$ ion, whereas in Conf4, it moves down towards the surface and bonds with two $\mathrm{Cu}$ and both surface and second-layer $\mathrm{O}$ ions.

In Conf4v, five surface $\mathrm{Ce}^{4+}$ ions are reduced to $\mathrm{Ce}^{3+}$, whereas four $\mathrm{Ce}^{4+}$ ions are reduced on the surface in the other structures. Clearly, the most negative adsorption energy of Conf $4 v$ can be related to the greatest number of reduced $\mathrm{Ce}^{3+}$ ions on the surface. The $\mathrm{Cu}_{4}$ total magnetic moment is $-0.409 \mu_{\mathrm{B}}$, taking $\mathrm{s}, \mathrm{p}$ and $\mathrm{d}$ orbitals into account. The two middle $\mathrm{Cu}$ atoms show a spin density isosurface around them, Fig. 11, and their 4s PDOS plots show two $4 \mathrm{~s}$ signatures with similar magnitude below $E_{\mathrm{F}}$ (see ESI, $\dagger$ Fig. S23). These observations suggest that three electrons are transferred from $\mathrm{Cu}_{4}$ to the surface, and one shared between the middle two $\mathrm{Cu}$ atoms, thus forming two $\mathrm{Cu}^{+}$ions with Bader charges of 0.470 and $0.598 e$, and two $\mathrm{Cu}^{\delta+}-\mathrm{Cu}^{\delta-}$ species with Bader charges of 0.361 and $-0.231 e$. Similarly, in Conf $2 \mathrm{v}, 3 \mathrm{v}$, and $7 \mathrm{v}$, three $\mathrm{Cu}^{\delta+}-\mathrm{Cu}^{0}$ species and one $\mathrm{Cu}^{+}$ion are formed on the surface (ESI, $\dagger$ Section S1.7).

Overall, we find that it is easier for a $\mathrm{Cu}_{4}$ cluster to retain and share one or more electrons between $\mathrm{Cu}$ atoms on a defective $\mathrm{CeO}_{2}$ (110) surface than on a stoichiometric surface, forming $\mathrm{Cu}^{+}$and $\mathrm{Cu}^{\delta+}-\mathrm{Cu}^{0}$ species close to the vacancy, which has been proposed as active sites for reactions such as carbonate hydrogenation. ${ }^{48}$

\subsection{Dispersion corrections}

We note from previous studies that the inclusion of dispersion corrections in the DFT $+U$ based calculations has a minimal effect on the local geometrical and electronic properties. ${ }^{47,49,50}$ 
Table $6 \mathrm{Cu}_{3} / \mathrm{CeO}_{2}(110)-\mathrm{Ov}$ and $\mathrm{Cu}_{4} / \mathrm{CeO}_{2}(110)-O v$ system: calculated total magnetic moment of the optimised structures and that of individual $\mathrm{Ce}^{3+}$ ions (s, p, d, f orbitals) in Bohr magneton $\left(\mu_{\mathrm{B}}\right)$; number of $\mathrm{Ce}^{3+}$ ions; average $\mathrm{Cu}-\mathrm{O}$ bond length shown in Fig. 10 and 11 , respectively $(\AA)$; average $\mathrm{Cu}-\mathrm{Cu}$ bond length $(\AA \AA)$; average $\mathrm{Ce}-\mathrm{O}$ bond length $(\AA)$ on the surface; adsorption energy per $\mathrm{Cu}$ atom $(\mathrm{eV})$

\begin{tabular}{|c|c|c|c|c|c|c|c|}
\hline System & $M_{\text {total }}\left(\mu_{\mathrm{B}}\right)$ & $M_{\mathrm{Ce}}\left(\mu_{\mathrm{B}}\right)$ & Number of $\mathrm{Ce}^{3+}$ reduced & $\mathrm{Cu}-\mathrm{O}(\AA)$ & $\mathrm{Cu}-\mathrm{Cu}(\AA)$ & $(\mathrm{Ce}-\mathrm{O})_{\text {surf }}(\AA)$ & $E_{\text {ad }}(\mathrm{eV})$ \\
\hline \multicolumn{8}{|c|}{$\mathrm{Cu}_{3} / \mathrm{CeO}_{2}(110)-\mathrm{Ov}$} \\
\hline Conf2v & 2.896 & $0.975 /-0.975 / 0.969 / 0.964 / 0.964$ & 5 & 1.795 & - & 2.351 & -3.350 \\
\hline Conf $3 v$ & 2.898 & $0.971 / 0.969 / 0.959$ & 3 & 1.796 & 2.258 & 2.345 & -2.420 \\
\hline Conf6v & 0.948 & $-0.972 / 0.969 / 0.952$ & 3 & 1.910 & 2.355 & 2.347 & -2.557 \\
\hline Conf7v & 2.888 & $0.971 / 0.969 / 0.950$ & 3 & 1.911 & 2.360 & 2.342 & -2.575 \\
\hline \multicolumn{8}{|c|}{$\mathrm{Cu}_{4} / \mathrm{CeO}_{2}(110)-\mathrm{Ov}$} \\
\hline Conf2v & -0.106 & $-0.972 / 0.967 / 0.856 /-0.956$ & 4 & 1.860 & 2.353 & 2.342 & -2.495 \\
\hline Conf3v & 0 & $-0.968 / 0.967 / 0.952 /-0.953$ & 4 & 1.861 & 2.357 & 2.341 & -2.586 \\
\hline Conf $4 v$ & -1.381 & $-0.974 / 0.965 / 0.962 /-0.964 /-0.961$ & 5 & 1.810 & 2.451 & 2.336 & -2.674 \\
\hline Conf7v & 0 & $0.972 /-0.967 / 0.963 /-0.958$ & 4 & 1.803 & 2.390 & 2.351 & -2.574 \\
\hline
\end{tabular}
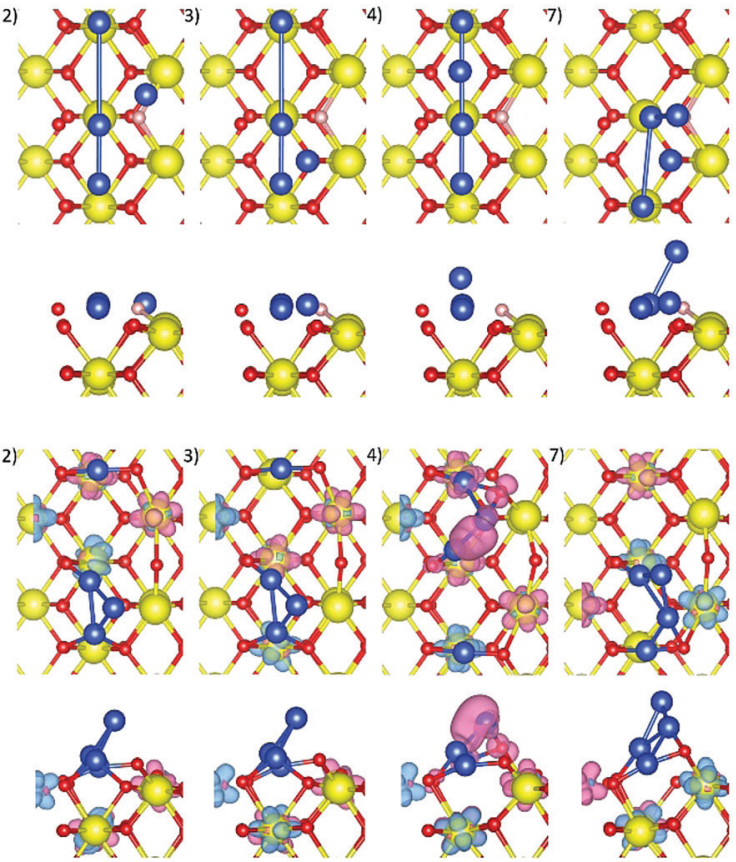

Fig. 11 Top row: Top view and side view of initial structures of Conf2v, 3v, $4 v$ and $7 v$, respectively, from the $\mathrm{Cu}_{4} / \mathrm{CeO}_{2}(110)$ system with one oxygen vacancy. The $\mathrm{Cu}_{3}$ clusters are emphasised by the $\mathrm{Cu}-\mathrm{Cu}$ bonds which may not physically exist. Bottom row: Top view and side view of the corresponding optimised structures of Conf2v, 3v, $4 v$ and $7 v$, respectively, with spin density isosurfaces of 0.005 e $\AA^{-3}$ around $\mathrm{Cu}$ and reduced $\mathrm{Ce}^{3+}$ ions

Therefore, in this study we have only investigated the configurations which have the most negative $\mathrm{Cu}$ adsorption energies based on the DFT $+U$ calculations, as listed in ESI, $\uparrow$ Table S3, and compared the structures and energetics without $(\mathrm{DFT}+U)$ and with the van der Waals dispersion term $(\mathrm{DFT}+U+\mathrm{D} 3)$. We find that for each of the nine configurations investigated, the inclusion of the D3 term only makes the adsorption energies slightly more negative (maximum difference less than $0.23 \mathrm{eV}$ ) which agrees with the previous work. ${ }^{47,49,50}$

\subsection{Discussion}

For $\mathrm{Cu}_{n}(n=1-4)$ adsorption on a stoichiometric $\mathrm{CeO}_{2}(110)$ surface, $\mathrm{a} \mathrm{Cu}_{n}$ cluster grows along the long bridge sites until
$\mathrm{Cu}_{3}$, so that each $\mathrm{Cu}$ atom can strongly interact with surface oxygen ions at these sites, forming stable structures, as illustrated in Fig. 12(1-3), which, however, limits $\mathrm{Cu}-\mathrm{Cu}$ interactions since they are distant from each other, hardly forming any $\mathrm{Cu}-\mathrm{Cu}$ bonds. A linear $\mathrm{Cu}_{3}$ cluster represents a component of a $\mathrm{Cu}$ monolayer structure on the surface, where long bridge sites are first occupied upon $\mathrm{Cu}$ adsorption with an increasing $\mathrm{Cu}$ loading. This monolayer then grows into a bilayer in a way suggested by the $\mathrm{Cu}_{3}$ to $\mathrm{Cu}_{4}$ transition, with long-bridge site $\mathrm{Cu}$ as anchoring sites. The fourth $\mathrm{Cu}$ either rises up from the surface (Fig. 12(4.3)) or moves down towards the surface, as illustrated in Fig. 12(4.4), in between two adjacent long bridge sites, to bridge $\mathrm{Cu}$ atoms and bond with surface/subsurface oxygen ions from two adjacent long bridge sites. In this $\mathrm{Cu}$ monolayer to bilayer transition, $\mathrm{Cu}-\mathrm{Cu}$ interactions gradually surpass in strength $\mathrm{Cu}-\mathrm{O}$ interactions and become the dominant factor, resulting in $\mathrm{Cu}$ atoms at the top layer occupying the space in between long bridge sites and bonding with bottomlayer $\mathrm{Cu}$ atoms as well as surface oxygen ions; or some $\mathrm{Cu}$ atoms may be incorporated into the surface, as again seen in Fig. 12(4.4), and as is observed experimentally. ${ }^{19,43}$ This $\mathrm{Cu}_{n}$ cluster growth pattern is also demonstrated by the trend of adsorption energy per $\mathrm{Cu}$ atom versus $\mathrm{Cu}_{n}$ cluster size, given in Fig. 13. From $\mathrm{Cu}_{1}$ to $\mathrm{Cu}_{2}$, the adsorption energy per $\mathrm{Cu}$ becomes more negative by $\sim 0.2 \mathrm{eV}$ to $-3.492 \mathrm{eV}$, indicating a slightly more stable $\mathrm{Cu}_{2}$ cluster than a $\mathrm{Cu}$ adatom on the surface, due to additional $\mathrm{Cu}-\mathrm{Cu}$ interactions besides surface $\mathrm{Cu}-\mathrm{O}$ interactions. The value then becomes slightly less negative at $-3.429 \mathrm{eV}$ at $\mathrm{Cu}_{3}$, which then changes by $\sim 0.5 \mathrm{eV}$ at $\mathrm{Cu}_{4}$. A similar $\mathrm{Cu}_{n}$ growth pattern is observed on a defective surface with one surface oxygen vacancy $\left(\mathrm{CeO}_{2}(110)-\mathrm{Ov}\right)$, as illustrated in Fig. 14, except we find that the $\mathrm{Cu}$ adatom on the defective surface has the most negative adsorption energy. However, $\mathrm{Cu}-\mathrm{O}$ interactions are significantly weakened because of oxygen vacancy formation, thus showing a less negative adsorption energy per $\mathrm{Cu}$ than that with a stoichiometric surface, which becomes even more substantial in the $\mathrm{Cu}_{3}$ to $\mathrm{Cu}_{4}$ transition, where the adsorption energy per $\mathrm{Cu}$ becomes less negative by $\sim 0.7 \mathrm{eV}$.

$\mathrm{Cu}_{n}$ adsorption energy, shown in Fig. 13, suggests that growth of $\mathrm{Cu}_{4}$ on $\mathrm{CeO}_{2}(110)$ with/out one surface oxygen vacancy is energetically less favoured, and $\mathrm{Cu}_{4}$ is likely to dissociate to $\mathrm{Cu}_{1-3}$. However, several experimental studies have 

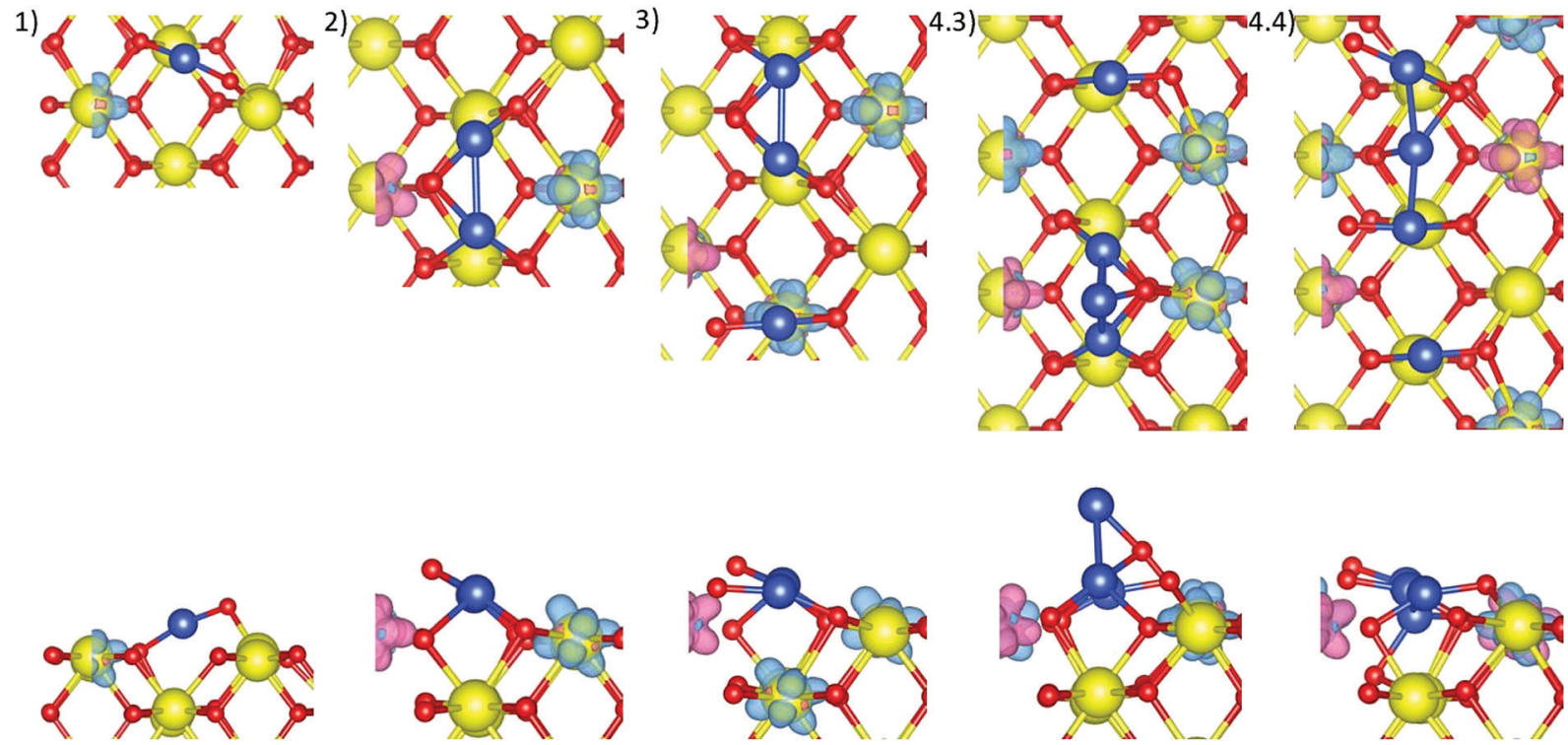

Fig. 12 Top view and side view of the most stable $\mathrm{Cu}_{n} / \mathrm{CeO}_{2}(110)(n=1-4)$ structures, labelled as (1) to (4); (4.3) and (4.4) are the optimised structures of Conf3 and 4, respectively, which have almost the same stability.

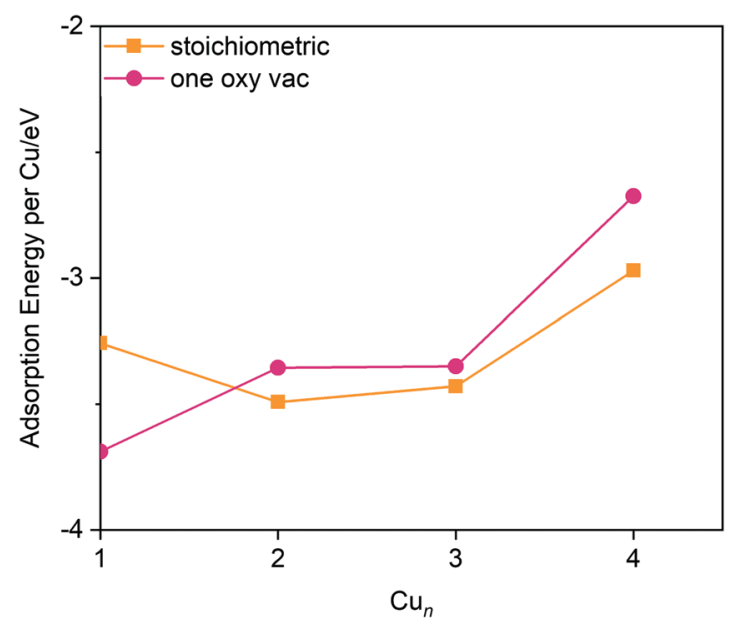

Fig. 13 Adsorption energy per $\mathrm{Cu}$ atom as a function of the $\mathrm{Cu}_{n}$ cluster size on a stoichiometric and a defective $\mathrm{CeO}_{2}(110)$ surface with one oxygen vacancy, respectively.

reported $\mathrm{Cu}$ bilayers and large $\mathrm{Cu}$ particles on $\mathrm{Cu} / \mathrm{CeO}_{2}$ nanorod catalysts, prepared in solutions by wet impregnation or deposition precipitation, ${ }^{8,11,51}$ suggesting that under kinetic conditions, for example, adsorption sites for single $\mathrm{Cu}$ atoms might become unavailable, or clustering of single $\mathrm{Cu}$ adsorbates may destabilise individual sites to some degree, formation of larger $\mathrm{Cu}$ clusters can become energetically preferable.

Analysis of electronic structures of the configurations having the lowest adsorption energy clearly demonstrates electron transfer from $\mathrm{Cu} 4 \mathrm{~s}$ to $\mathrm{Ce} 4 \mathrm{f}$ orbitals, readily reducing the $\mathrm{CeO}_{2}(110)$ surface both with and without a surface oxygen vacancy. A maximum of four $\mathrm{Ce}^{3+}$ ions are found for a $\mathrm{Cu}_{n}$ l $\mathrm{CeO}_{2}(110)(n=1-4)$ system, and a maximum of five $\mathrm{Ce}^{3+}$ ions for

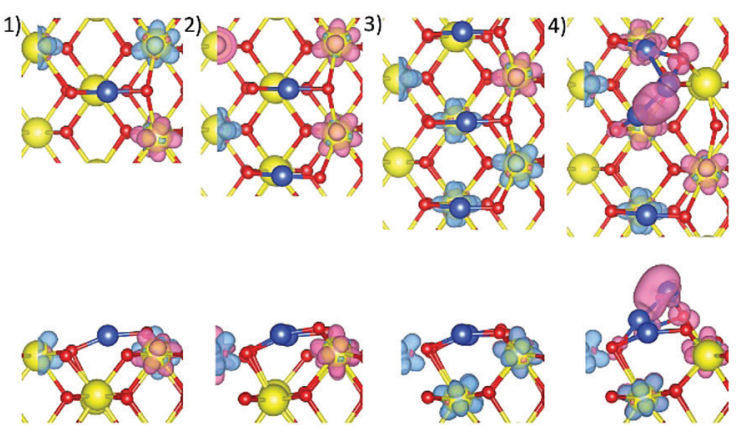

Fig. 14 Top view and side view of the most stable $\mathrm{Cu}_{n} / \mathrm{CeO}_{2}(110)-\mathrm{Ov}$ $(n=1-4)$ structures with the spin density isosurfaces of 0.005 e $\AA^{-3}$ around $\mathrm{Cu}$ and reduced $\mathrm{Ce}^{3+}$ ions, labelled as (1) to (4).

a $\mathrm{Cu}_{n} / \mathrm{CeO}_{2}(110)-\mathrm{Ov}(n=1-4)$ system. Both surface and secondlayer $\mathrm{Ce}^{3+}$ ions are formed, but the latter is energetically less favoured. Other metastable $\mathrm{Cu}_{n} / \mathrm{CeO}_{2}(110)$ structures also possess interesting electronic structures, in which either an electron pair with opposite spins or a single electron is observed on the $\mathrm{Cu}_{n}$. For example, calculations of the metastable $\mathrm{Cu}_{4} / \mathrm{CeO}_{2}(110)$-Conf2 structure show coexistence of $\mathrm{Cu}^{+}$, $\mathrm{Cu}^{2+}$, and a topmost $\mathrm{Cu}^{\delta-}$ species, and intriguing $\mathrm{Cu}^{+} / \mathrm{Cu}^{2+}$ interchange at the $\mathrm{Cu} / \mathrm{CeO}_{2}$ interface which has been reported as providing active sites for many reactions. ${ }^{6,10,17}$ In addition, surface oxygen vacancy formation makes it easier for a $\mathrm{Cu}_{4}$ cluster to retain and share one or more electrons between $\mathrm{Cu}$ atoms, forming mixed $\mathrm{Cu}^{+}$and $\mathrm{Cu}^{\delta+}-\mathrm{Cu}^{0}$ species close to the vacancy. The coexisting $\mathrm{Cu}^{+}$and $\mathrm{Cu}^{0}$ species of a $\mathrm{Cu}$ bilayer at the $\mathrm{Cu} / \mathrm{CeO}_{2}$ interface has been proposed as actives sites for reactions such as carbonate hydrogenation. ${ }^{48}$

By an extensive study of different possible $\mathrm{Ce}^{3+}$ electron spin arrangement of 38 configurations from both systems, we find 
that structures with an antiferromagnetic $\mathrm{CeO}_{2}(110)$ or $\mathrm{CeO}_{2}(110)-\mathrm{Ov}$ surface are energetically favourable (see ESI, $\dagger$ Table S2) in most cases, with a maximum reduction in the adsorption energy of $0.18 \mathrm{eV}$, which strongly suggests that $\mathrm{CeO}_{2}(110)$ in both systems does not show any ferromagnetic (FM) behaviour, as reported previously. ${ }^{52}$

A few previous studies of $\mathrm{Cu}$ and $\mathrm{Cu}_{n}$ adsorbed on other metal oxide surfaces, such as $\mathrm{ZnO}, \mathrm{MgO}, \mathrm{TiO}_{2}$, and $\mathrm{SrTiO}_{3}$, are also briefly discussed here and compared with our study. For non-reducible surfaces such as $\mathrm{ZnO}$ and $\mathrm{MgO}, \mathrm{Cu}$-surface metal cation interactions predominate. For example, on $\mathrm{Zn}$ terminated (0001) surface of $\mathrm{ZnO}$, French et al. ${ }^{53}$ observed that neutrally charged $\mathrm{Cu}$ clusters were mainly attracted to $\mathrm{Zn}$ cations, and that charged $\mathrm{Cu}$ clusters had charges mostly localised on the anchoring $\mathrm{Cu}$ adatom, thus showing effectively charge neutral surface copper sites. They concluded that larger copper clusters were predominantly charge neutral, as electrostatic repulsion destabilised $\mathrm{Cu}^{+}$ions. They ${ }^{54}$ later reported that copper atoms in the middle layer of planar and polyhedral clusters gained a small amount of charges from surface oxygen ions. For +2 charged Cu clusters, electron transfer from oxygens to the anchoring $\mathrm{Cu}$ facilitated interactions between secondlayer $\mathrm{Cu}$ and surface $\mathrm{Zn}$ cations, thus promoting formation of polyhedral $\mathrm{Cu}$ clusters, with the formed $\mathrm{Cu}^{x+}$ sites being the nucleation centres. Mora-Fonz et $a l^{55}$ reported $\mathrm{Cu}$ adsorption energy on non-polar (1010) surface of $\mathrm{ZnO}$, in a range of $0.365-$ $1.981 \mathrm{eV}$. On reconstructed polar Zn-terminated (0001) and O-terminated (0001) surface, Higham et al. ${ }^{56}$ found that planar and 3D Cu cluster growth were favoured, respectively, because of strong attractive $\mathrm{Cu}-\mathrm{Zn}$ and repulsive $\mathrm{Cu}-\mathrm{O}$ interactions. On the O-rich Zn-terminated reconstructed surface, they also observed close interaction between $\mathrm{Cu}$ and surface oxygens, with electron transfer from coordinating $\mathrm{Cu}$ atoms to surface O ions.

Pacchioni and Rösch ${ }^{57}$ found that $\mathrm{Cu}-\mathrm{Cu}$ interactions were stronger than $\mathrm{Cu}$-surface interactions, in $\mathrm{Cu}_{4}$ adsorption on $\mathrm{MgO}(110)$. $\mathrm{Cu}$ and $\mathrm{Cu}_{4}$ were weakly oxidised by surface oxygens, showing a weak polar covalent bond with limited charge transfer from $\mathrm{Cu} 4 \mathrm{~s}$ to surface $\mathrm{O} 2 \mathrm{p}$, with adsorption energies of 0.34 and $0.36 \mathrm{eV}$, respectively. Geudtner et $a{ }^{58}{ }^{58}$ later revealed that $\mathrm{Cu}-\mathrm{Cu}$ interactions were the dominating factor in larger $\mathrm{Cu}_{n}(n=2-6)$ cluster formation on $\mathrm{MgO}(100)$, stronger than $\mathrm{Cu}-$ surface oxygen interactions, with reported adsorption energies of $1.91-2.31 \mathrm{eV}$.

For $\mathrm{Cu}$ adsorption on reducible surfaces such as $\mathrm{TiO}_{2}$, it was reported that $\mathrm{Cu}$ adatom bound strongly to $\mathrm{TiO}_{2}(110)$ nearer to

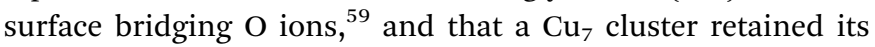
pentagonal bipyramidal structure on $\mathrm{TiO}_{2}$ surface, because of strong $\mathrm{Cu}-\mathrm{O}$ and weak $\mathrm{Cu}-\mathrm{Ti}$ interactions. ${ }^{60,61}$ Natile et al. ${ }^{62}$ reported $\mathrm{Cu}_{2}$ adsorption on $\mathrm{SrTiO}_{3}(100)$ with an adsorption energy of $-1.74 \mathrm{eV}$, and observed strong interactions between $\mathrm{Cu}$ and surface oxygens.

Ceria is highly reducible, and electron transfer from $\mathrm{Cu}_{n}$ to surface $\mathrm{Ce}^{4+}$ is clearly observed upon $\mathrm{Cu}_{n}$ adsorption on $\mathrm{CeO}_{2}(110)$, which, is very different from that on non-reducible surfaces such as $\mathrm{ZnO}$ and $\mathrm{MgO}$, where $\mathrm{Cu}$-surface metal cation interactions predominate, with a small amount of charge transfer either from $\mathrm{Cu}$ clusters to surface oxygens or vice versa, depending on the exact model studied. Yet, our detailed study of small $\mathrm{Cu}_{n}(n=1-4)$ cluster adsorption on $\mathrm{CeO}_{2}(110)$ agrees in general with the aforementioned studies of $\mathrm{TiO}_{2}$, that coppermetal oxide interactions are important in determining geometry and stability of $\mathrm{Cu} / \mathrm{metal}$ oxide structures. ${ }^{60}$ The calculated adsorption energies of $\mathrm{Cu}_{n}$ on $\mathrm{CeO}_{2}(110)$, absolute values of 2.971-3.492 eV, are generally higher than the abovementioned values for other surfaces, suggesting strong interactions between copper and ceria. In addition, experimental studies reported that nanostructured $\mathrm{Cu} / \mathrm{CeO}_{2}$ catalysts had a copper particle sizeactivity dependence, ${ }^{51}$ which thus strongly stimulates further study of larger $\mathrm{Cu}$ cluster adsorption on $\mathrm{CeO}_{2}(110)$.

\section{Conclusions}

The atomic and electronic structures of a $\mathrm{Cu}_{n}(n=1-4)$ cluster adsorbed on either a stoichiometric $\mathrm{CeO}_{2}(110)$ surface or a defective surface with one oxygen vacancy $\left(\mathrm{CeO}_{2}-\mathrm{Ov}\right)$ have been investigated by DFT calculations without using pre-assumed $\mathrm{Cu}_{n}$ cluster shapes. Both the stoichiometric and defective surface are readily reduced upon $\mathrm{Cu}_{n}$ adsorption, forming surface and second-layer $\mathrm{Ce}^{3+}$ ions, and do not show any $\mathrm{FM}$ behaviour. On both surfaces, $\mathrm{Cu}_{1}$ grows to $\mathrm{Cu}_{3}$ along the long bridge sites, forming strong $\mathrm{Cu}-\mathrm{O}$ bonds at adjacent long bridge sites, which models a $\mathrm{Cu}$ monolayer growth mechanism. The $\mathrm{Cu}_{3}$ to $\mathrm{Cu}_{4}$ transition suggests that this monolayer then begins to grow into a bilayer, with long-bridge site $\mathrm{Cu}$ as anchoring sites, where top-layer $\mathrm{Cu}$ atoms ${ }^{11}$ occupy the space in between long bridge sites to bond strongly with bottom-layer $\mathrm{Cu}$ and surface oxygens; or some $\mathrm{Cu}$ atoms are incorporated into the $\mathrm{CeO}_{2}(110)$ surface lattice, as observed experimentally. ${ }^{19,43}$ Surface oxygen vacancy formation however weakens $\mathrm{Cu}-\mathrm{O}$ interactions at the surface, thus making $\mathrm{Cu}$ adsorption energy less negative.

$\mathrm{A} \mathrm{Cu}$ bilayer is rich in $\mathrm{Cu}^{+}$species at the $\mathrm{Cu}-\mathrm{O}$ interface (four $\mathrm{Cu}^{+}$in $\mathrm{Cu}_{4} / \mathrm{CeO}_{2}$, two $\mathrm{Cu}^{+}$and two $\mathrm{Cu}^{\delta+}$ in $\mathrm{Cu}_{4} / \mathrm{CeO}_{2}-\mathrm{Ov}$ ), agreeing with experimental results. ${ }^{11}$ In metastable structures, it also shows $\mathrm{Cu}^{2+}$ and $\mathrm{Cu}^{\delta-}$ species, and $\mathrm{Cu}^{\delta+}-\mathrm{Cu}^{0}$ species on a stoichiometric and a defective surface, respectively. This interesting $\mathrm{Cu}^{2+} / \mathrm{Cu}^{+}$and $\mathrm{Cu}^{+} / \mathrm{Cu}^{0}$ interplay observed in our work thus give a theoretical basis to many experimental studies where the $\mathrm{Cu}^{2+} / \mathrm{Cu}^{+}$pair and the $\mathrm{Cu}^{+} / \mathrm{Cu}^{0}$ pair were proposed as active sites for $\mathrm{CuO}_{x} / \mathrm{CeO}_{2}$-nanorod catalysts in many reactions. ${ }^{6,10,17,48}$ In the future work we will explore the structures and energetics of larger $\mathrm{Cu}$ clusters adsorbed on the $\mathrm{CeO}_{2}(110)$ surface.

\section{Conflicts of interest}

There are no conflicts to declare.

\section{Acknowledgements}

Rui Zhang thanks the Department of Chemical Engineering, Imperial College London for the award of a Department 
Scholarship. This study was initiated under the EPSRC Low Carbon Fuels programme EP/N009533/1 \& EP/N010531/1. We thank Dr Richardo Grau-Crespo for his helpful discussions on modelling the $\mathrm{Ce}^{4+}$ to $\mathrm{Ce}^{3+}$ reduction process. We also thank Dr David Mora-Fonz for his helpful discussions and suggestions. This work used the computing resources from the ARCHER UK National Super-computing Service http:/www.archer.ac.uk/, the THOMAS and the YOUNG UK National Tier 2 Supercomputing Service, via our membership of the UK's HEC Materials Chemistry Consortium (MCC), which is funded by EPSRC (EP/L000202). This work also used the UK Materials and Molecular Modelling Hub for computational resources, MMM Hub, which is partially funded by EPSRC (EP/P020194 and EP/ T022213). We also thank UCL for access to the KATHLEEN and Faraday computing facilities. We also acknowledge the use of HPC Midlands Plus (funded by the EPSRC (grant EP/P020232/ 1)) and Cirrus (funded by the University of Edinburgh and EPSRC(EP/PO20267/1)).

\section{References}

1 T. Montini, M. Melchionna, M. Monai and P. Fornasiero, Chem. Rev., 2016, 116, 5987-6041.

2 J. Paier, C. Penschke and J. Sauer, Chem. Rev., 2013, 113, 3949-3985.

3 J. Kaspar, P. Fornasiero and M. Graziani, Catal. Today, 1999, 50, 285-298.

4 A. Trovarelli, Catal. Rev., 1996, 38, 439-520.

5 W.-W. Wang, W.-Z. Yu, P.-P. Du, H. Xu, Z. Jin, R. Si, C. Ma, S. Shi, C.-J. Jia and C.-H. Yan, ACS Catal., 2017, 7, 1313-1329.

6 M. Zabilskiy, P. Djinović, E. Tchernychova, O. P. Tkachenko, L. M. Kustov and A. Pintar, ACS Catal., 2015, 5, 5357-5365.

7 H. X. Mai, L. D. Sun, Y. W. Zhang, R. Si, W. Feng, H. P. Zhang, H. C. Liu and C. H. Yan, J. Phys. Chem. B, 2005, 109, 24380-24385.

8 A. Chen, X. Yu, Y. Zhou, S. Miao, Y. Li, S. Kuld, J. Sehested, J. Liu, T. Aoki, S. Hong, M. F. Camellone, S. Fabris, J. Ning, C. Jin, C. Yang, A. Nefedov, C. Wöll, Y. Wang and W. Shen, Nat. Catal., 2019, 2, 334-341.

9 S. Y. Yao, W. Q. Xu, A. C. Johnston-Peck, F. Z. Zhao, Z. Y. Liu, S. Luo, S. D. Senanayake, A. Martínez-Arias, W. J. Liu and J. A. Rodriguez, Phys. Chem. Chem. Phys., 2014, 16, 17183-17195.

10 L. Kang, B. Wang, Q. Bing, M. Zalibera, R. Buchel, R. Xu, Q. Wang, Y. Liu, D. Gianolio, C. C. Tang, E. K. Gibson, M. Danaie, C. Allen, K. Wu, S. Marlow, L. D. Sun, Q. He, S. Guan, A. Savitsky, J. J. Velasco-Velez, J. Callison, C. W. M. Kay, S. E. Pratsinis, W. Lubitz, J. Y. Liu and F. R. Wang, Nat. Commun., 2020, 11, 4008.

11 J. Ning, C. Dong, M. Li, Y. Zhou and W. Shen, J. Chem. Phys., 2020, 152, 094708.

12 J. C. Conesa, Surf. Sci., 1995, 339, 337-352.

13 L. Szabová, M. F. Camellone, M. Huang, V. Matolin and S. Fabris, J. Chem. Phys., 2010, 133, 234705.
14 Z. Yang, L. Xie, D. Ma and G. Wang, J. Phys. Chem. C, 2011, 115, 6730-6740.

15 L. O. Paz-Borbon, F. Buendia, I. L. Garzon, A. PosadaAmarillas, F. Illas and J. Li, Phys. Chem. Chem. Phys., 2019, 21, 15286-15296.

16 J. F. Jerratsch, X. Shao, N. Nilius, H. J. Freund, C. Popa, M. V. Ganduglia-Pirovano, A. M. Burow and J. Sauer, Phys. Rev. Lett., 2011, 106, 246801.

17 S. Yao, K. Mudiyanselage, W. Xu, A. C. Johnston-Peck, J. C. Hanson, T. Wu, D. Stacchiola, J. A. Rodriguez, H. Zhao, K. A. Beyer, K. W. Chapman, P. J. Chupas, A. Martínez-Arias, R. Si, T. B. Bolin, W. Liu and S. D. Senanayake, ACS Catal., 2014, 4, 1650-1661.

18 L. Lin, S. Yao, Z. Liu, F. Zhang, N. Li, D. Vovchok, A. Martínez-Arias, R. Castañeda, J. Lin, S. D. Senanayake, D. Su, D. Ma and J. A. Rodriguez, J. Phys. Chem. C, 2018, 122, 12934-12943.

19 L. Liu, Z. Yao, Y. Deng, F. Gao, B. Liu and L. Dong, ChemCatChem, 2011, 3, 978-989.

20 M. Nolan, J. Chem. Phys., 2012, 136, 134703.

21 L. Cui, Y. Tang, H. Zhang, L. G. Hector, Jr., C. Ouyang, S. Shi, H. Li and L. Chen, Phys. Chem. Chem. Phys., 2012, 14, 1923-1933.

22 A. Chutia, E. K. Gibson, M. R. Farrow, P. P. Wells, D. O. Scanlon, N. Dimitratos, D. J. Willock and C. R. A. Catlow, Phys. Chem. Chem. Phys., 2017, 19, 27191-27203.

23 Z. Ren, N. Liu, B. Chen, J. Li and D. Mei, J. Phys. Chem. C, 2018, 122, 27402-27411.

24 J. Kullgren, K. Hermansson and C. Castleton, J. Chem. Phys., 2012, 137, 044705.

25 G. Kresse and J. Hafner, Phys. Rev. B: Condens. Matter Mater. Phys., 1993, 47, 558-561.

26 G. Kresse and J. Hafner, Phys. Rev. B: Condens. Matter Mater. Phys., 1994, 49, 14251-14269.

27 G. Kresse and J. Furthmüller, Phys. Rev. B: Condens. Matter Mater. Phys., 1996, 54, 11169-11186.

28 P. E. Blöchl, Phys. Rev. B: Condens. Matter Mater. Phys., 1994, 50, 17953-17979.

29 J. P. Perdew, K. Burke and M. Ernzerhof, Phys. Rev. Lett., 1996, 77, 3865-3868.

30 G. Makov and M. C. Payne, Phys. Rev. B: Condens. Matter Mater. Phys., 1995, 51, 4014-4022.

31 J. Neugebauer and M. Scheffler, Phys. Rev. B: Condens. Matter Mater. Phys., 1992, 46, 16067-16080.

32 H. J. Monkhorst and J. D. Pack, Phys. Rev. B: Solid State, 1976, 13, 5188-5192.

33 V. V. Anisimov, J. Zaanen and O. K. Andersen, Phys. Rev. B: Condens. Matter Mater. Phys., 1991, 44, 943-954.

34 V. V. Anisimov, I. I. Solovyev, M. A. Korotin, M. T. Czyzyk and G. A. Sawatzky, Phys. Rev. B: Condens. Matter Mater. Phys., 1993, 48, 16929-16934.

35 I. I. Solovyev, P. H. Dederichs and V. V. Anisimov, Phys. Rev. B: Condens. Matter Mater. Phys., 1994, 50, 16861-16871.

36 S. L. Dudarev, G. A. Botton, S. Y. Savrasov, C. J. Humphreys and A. P. Sutton, Phys. Rev. B: Condens. Matter Mater. Phys., 1998, 57, 1505-1509. 
37 H. Raebiger, S. Lany and A. Zunger, Phys. Rev. B: Condens. Matter Mater. Phys., 2007, 76, 045209.

38 E. L. Wilson, R. Grau-Crespo, C. L. Pang, G. Cabailh, Q. Chen, J. A. Purton, C. R. A. Catlow, W. A. Brown, N. H. de Leeuw and G. Thornton, J. Phys. Chem. C, 2008, 112, 10918-10922.

39 N. C. Hernández, R. Grau-Crespo, N. H. de Leeuw and J. F. Sanz, Phys. Chem. Chem. Phys., 2009, 11, 5246-5252.

40 M. M. Branda, N. J. Castellani, R. Grau-Crespo, N. H. de Leeuw, N. C. Hernandez, J. F. Sanz, K. M. Neyman and F. Illas, J. Chem. Phys., 2009, 131, 094702.

41 W. Tang, E. Sanville and G. Henkelman, J. Phys.: Condens. Matter, 2009, 21, 084204.

42 K. Momma and F. Izumi, J. Appl. Crystallogr., 2011, 44, 1272-1276.

43 D. Gamarra, A. L. Cámara, M. Monte, S. B. Rasmussen, L. E. Chinchilla, A. B. Hungría, G. Munuera, N. Gyorffy, Z. Schay, V. C. Corberán, J. C. Conesa and A. Martínez-Arias, Appl. Catal., B, 2013, 130-131, 224-238.

44 Z. Yang, T. K. Woo, M. Baudin and K. Hermansson, J. Chem. Phys., 2004, 120, 7741-7749.

45 S. Fabris, G. Vicario, G. Balducci, S. de Gironcoli and S. Baroni, J. Phys. Chem. B, 2005, 109, 22860-22867.

46 M. Nolan, D. G. Parker and G. W. Watson, Surf. Sci., 2005, 595, 223-232.

47 A. Chutia, D. J. Willock and C. R. A. Catlow, Faraday Discuss., 2018, 208, 123-145.

48 Y. Cui and W.-L. Dai, Catal. Sci. Technol., 2016, 6, 7752-7762.
49 L. Chen, T. V. W. Janssens and H. Gronbeck, Phys. Chem. Chem. Phys., 2019, 21, 10923-10930.

50 M. Delarmelina, M. G. Quesne and C. R. A. Catlow, Phys. Chem. Chem. Phys., 2020, 22, 6660-6676.

51 J. Zhu, Y. Su, J. Chai, V. Muravev, N. Kosinov and E. J. M. Hensen, ACS Catal., 2020, 10, 11532-11544.

52 P. R. Keating, D. O. Scanlon and G. W. Watson, J. Phys.: Condens. Matter, 2009, 21, 405502.

53 S. A. French, A. A. Sokol, S. T. Bromley, C. R. A. Catlow and P. Sherwood, Top. Catal., 2003, 24, 161-172.

54 S. A. French, A. A. Sokol, C. R. A. Catlow and P. Sherwood, J. Phys. Chem. C, 2008, 112, 7420-7430.

55 D. Mora-Fonz, T. Lazauskas, S. M. Woodley, S. T. Bromley, C. R. A. Catlow and A. A. Sokol, J. Phys. Chem. C, 2017, 121, 16831-16844.

56 M. D. Higham, D. Mora-Fonz, A. A. Sokol, S. M. Woodley and C. R. A. Catlow, J. Mater. Chem. A, 2020, 8, 22840-22857.

57 G. Pacchioni and N. Rösch, J. Chem. Phys., 1996, 104, 7329.

58 G. Geudtner, K. Jug and A. M. Köster, Surf. Sci., 2000, 467, 98-106.

59 D. Pillay, Y. Wang and G. S. Hwang, Korean J. Chem. Eng., 2004, 21, 537-547.

60 S. M. Shearin, Mod. Concepts Mater. Sci., 2020, 2, 1-6.

61 Y. Lan, Y. Xie, J. Chen, Z. Hu and D. Cui, Chem. Commun., 2019, 55, 8068-8071.

62 M. M. Natile, S. Carlotto, G. Bizzotto, A. Vittadini and A. Glisenti, Eur. J. Inorg. Chem., 2018, 3829-3834. 